\title{
The clinical efficacy of continuous renal replacement in the treatment of acute pancreatitis: a meta-analysis of randomized controlled trials
}

sijia $\mathrm{Ma}^{1}$, mingming Zhao ${ }^{1}$, zhiyu $\mathrm{Pan}^{1}$, jiao Fan ${ }^{1}$, xuexue Zhang ${ }^{1}$, and yu zhang ${ }^{1}$

${ }^{1}$ Affiliation not available

February 11, 2021

\begin{abstract}
Abstract:Objective: The purpose of this study was to investigate the effect of continuous renal replacement therapy(CRRT) on patients with acute pancreatitis(AP). Methods: A comprehensive search of seven databases without language restrictions includes PubMed, Cochrane Library, Scopus, Embase, Web of Science, China National Knowledge Infrastructure(CNKI) and Wan fang database. Randomized controlled trials (RCTs) for the treatment of acute pancreatitis with CRRT were searched. All the included literatures were published before December 2020. Two review authors independently selected the study and extracted the data according to the inclusion criteria. A third review author will and discuss with the first two review authors and resolve the differences. Weighted mean difference(WMD), risk ratio (RR), and 95\% confidence interval (CI) were used for estimating the clinical efficacy of AP in CRRT and control treatment. Results: Fifty-three RCTs met the inclusion criteria and were used in the meta-analysis, with a total of 3,382 effective samples. A comprehensive review of the system shows that the mortality rate of the CRRT group was significantly lower than that of the control group, and the difference was statistically significant $(\mathrm{RR}=0.44,95 \% \mathrm{CI} 0.34$ to $0.57, \mathrm{P}<0.000001)$, the patients using CRRT had lower APACHE II scores level $(\mathrm{WMD}=-3.78$, 95\% CI-4.66 to $-2.90, \mathrm{P}<0.00001)$, higher CRP, PCT,TNF- and IL-6 clearance effect. According to liver function, the patients using CRRT had lower ALT and AST levels. In the same way, according to renal function, the patients using CRRT had lower $\mathrm{SCr}(\mathrm{WMD}=-94.28,95 \% \mathrm{CI}-125.47$ to $-63.10, \mathrm{P}<0.00001)$. The patients using CRRT also had higher ALB levels $(\mathrm{WMD}=2.32$, $95 \%$ CI-1.05 to $3.59, \mathrm{P}=0.0003)$. Moreover, Results shown no statistical difference in Serum potassium level (WMD=-0.00, 95\% CI-0.31 to $0.31, \mathrm{P}=1.00$ ) between the two groups. Conclusions: Our findings suggest that treatment with CRRT for acute pancreatitis may be more beneficial than conventional treatment. However, high-quality studies with a larger sample size are still needed to confirm our results.
\end{abstract}

The clinical efficacy of continuous renal replacement in the treatment of acute pancreatitis: a meta-analysis of randomized controlled trials

Sijia Ma ${ }^{1}$, Mingming Zhao ${ }^{1}$, Zhiyu Pan ${ }^{1}$, Jiao Fan ${ }^{1}$, Zhang XueXue ${ }^{2}$ Yu Zhang ${ }^{1 *}$

1 Department of Nephrology, Xiyuan Hospital, China Academy of Chinese Medical Sciences, Beijing, China

2 Department of endocrinology, China Academy of Chinese Medical Sciences, Beijing, China

*Correspondence: zhangyu8225@126.com

Sijia Ma, Mingming Zhao are shared first authors and contributed equally to the article.

Abstract: Objective:The purpose of this study was to investigate the effect of continuous renal replacement therapy(CRRT) on patients with acute pancreatitis(AP). Methods: A comprehensive search of seven databases without language restrictions includes PubMed, Cochrane Library, Scopus, Embase, Web of Science, China National Knowledge Infrastructure(CNKI) and Wan fang database. Randomized controlled 
trials (RCTs) for the treatment of acute pancreatitis with CRRT were searched. All the included literatures were published before December 2020. Two review authors independently selected the study and extracted the data according to the inclusion criteria. A third review author will and discuss with the first two review authors and resolve the differences. Weighted mean difference(WMD), risk ratio (RR), and 95\% confidence interval (CI) were used for estimating the clinical efficacy of AP in CRRT and control treatment. Results: Fifty-three RCTs met the inclusion criteria and were used in the meta-analysis, with a total of 3,382 effective samples. A comprehensive review of the system shows that the mortality rate of the CRRT group was significantly lower than that of the control group, and the difference was statistically significant $(\mathrm{RR}=0.44,95 \% \mathrm{CI} 0.34$ to $0.57, \mathrm{P}<0.000001)$, the patients using CRRT had lower APACHE II scores level(WMD=-3.78, 95\%CI-4.66 to $-2.90, \mathrm{P}<0.00001)$, higher CRP, PCT,TNF- $\alpha$ and IL-6 clearance effect. According to liver function, the patients using CRRT had lower ALT and AST levels. In the same way, according to renal function, the patients using CRRT had lower SCr (WMD=-94.28, 95\%CI-125.47 to $-63.10, \mathrm{P}<0.00001)$. The patients using CRRT also had higher ALB levels(WMD=2.32, 95\% CI-1.05 to $3.59, \mathrm{P}=0.0003)$. Moreover, Results shown no statistical difference in Serum potassium level (WMD=-0.00, $95 \% \mathrm{CI}-0.31$ to $0.31, \mathrm{P}=1.00)$ between the two groups. Conclusions : Our findings suggest that treatment with CRRT for acute pancreatitis may be more beneficial than conventional treatment. However, high-quality studies with a larger sample size are still needed to confirm our results.

Key words: Acute pancreatitis; Continuous renal replacement therapy; The prognosis; Meta-analysis; APACHE II scores; Serum markers; Inflammatory factors; Liver and kidney function

\section{Introduction}

Acute pancreatitis(AP), an inflammatory disorder of the pancreas, is the leading cause of admission to hospital for gastrointestinal disorders in many countries $^{1}$, it is one of the common acute abdominal diseases. The incidence rate of acute pancreatitis is rising globally, which sharp increasing its burden on healthcare services ${ }^{2}$.Acute pancreatitis is an inflammatory response of pancreatic tissue to self-digestion, edema, bleeding and even necrosis after pancreatin activation in the pancreas due to various etiologies. The most likely causes of pancreatitis are Alcoholism, gallstones ${ }^{3}$.Because the severity of acute pancreatitis is different, clinical acute pancreatitis is divided into three types: mild, medium and severe, while according to the type of inflammation, acute pancreatitis can be divided into interstitial edema pancreatitis or necrotizing pancreatitis. ${ }^{4}$ About $80 \%$ to $85 \%$ of patients will develop only mild acute pancreatitis, while about $15 \%$ to $20 \%$ of patients will develop severe acute pancreatitis with severe organ failure and local complications, which may even lead to death ${ }^{5}$.

The main clinical manifestations of acute pancreatitis are abdominal pain, nausea, vomiting, high fever, jaundice, peritoneal irritation and so $\mathrm{on}^{6}$. AP is a digestive system disease which caused by a variety of factors and characterized by acute inflammation of the pancreas and histologically acinar cell destruction. Two of the following three criterias can be defined as acute pancreatitis: abdominal pain, serum amylase and lipase thresholds typically three times the upper limit, and imaging criteria (computed tomography, magnetic resonance imaging, ultrasound $)^{7}$. Lysosome function is disturbed, a series of digestive enzymes are activated abnormally, leading to digestive damage and local inflammation. It has been demonstrated that acini damage can stimulate inflammation in the pancreatic parenchyma due to the pancreas's own digestive process(like filtration of neutrophils and macrophages, and release of cytokines, tumor necrosis factor, and interleukin$1,6$, and 8$)^{8}$. Therefore, intervention for acute pancreatitis is very important. The conventional treatment of acute pancreatitis is mainly to reduce the secretion of pancreatic fluid and reduce the pancreas's self-digestion as much as possible. This usually involve fasting and water prohibition, gastrointestinal decompression, use of somatostatin and its analogs, thus inhibition of gastric acid secretion. Fluid resuscitation, enteral nutrition, and antibiotics to treat infections, suppress inflammation, and prevent organ failure ${ }^{9}$. However, some evidence suggest that prophylactic antibiotic used in patients with acute pancreatitis is not associated with significant reductions in mortality or morbidity recently. Therefore, routine prophylactic antibiotics are no longer recommended for all patients with acute pancreatitis ${ }^{10}$. Antibiotics are the first choice for the treatment of infectious severe acute pancreatitis. Whereas, diagnosis is a challenge because the clinical 
presentation is indistinguishable from other infectious complications or inflammatory states associated with acute pancreatitis. How to choose more specific antibiotics for different patients has also become one of the difficult problems. With the development of science and technology, the continuous renal replacement therapy (CRRT) become one of the new methods of renal replacement therapy. Since it has to maintain electrolyte balance, regulate acid-base degree of fluid and waste from the blood metabolic, inflammatory mediator and endotoxin, thereby protect endothelial cells, help regulate the body's immune function, it not only can be widely used in acute and chronic renal failure, can also play an important role in the treatment of $\mathrm{AP}^{11}$.Compared with conventional treatment, does CRRT have a more beneficial effect on the treatment of patients? Does it reduce inflammation more in patients with acute pancreatitis? What about the function of liver and kidney of patient and viscera maintenance respect? Up to now, no one has evaluated CRRT versus conventional treatment for acute pancreatitis in these areas. Through this study, the effect of CRRT on the treatment effect and prognosis of AP was systematically evaluated to explore whether CRRT was a necessary way to treat AP and provide evidence-based medicine basis for the treatment of AP.

\section{Methods}

This meta-analysis performed followed the Preferred Reporting Items for Systematic Reviews and Metaanalysis (PRISMA) guidelines. The review protocol has been registered in PROSPERO (CRD42020220897), which is a systematic review of online international prospective registrations, planned by the National Institutes of Health Research.

\subsection{Search Strategy}

Electronic databases which including PubMed, Cochrane Library, Scopus, Embase, Web of Science, China National Knowledge Infrastructure(CNKI) and Wan fang database were searched. These following keywords were used individually or in a combined manner for the online literature: Continuous Renal Replacement Therapy OR Continuous RRT OR Continuous Renal Replacement Therapy OR Continuous Venovenous Hemodiafiltration OR CVVHDF OR Continuous Veno-Venous Hemodiafiltration OR Slow Continuous Ultrafiltration OR SCUF Technique OR CVVH Technique OR Continuous Veno-Venous Hemofiltration OR CAVHD OR Continuous Venovenous Hemodialysis OR CVVHD OR Continuous Veno-Venous Hemodialysis AND Acute Pancreatitis OR Acute Edematous Pancreatitides. Two reviewers (SJ Ma and MM Zhao) independently review the titles, keywords, and abstracts of the literature selected in these format, when they encounter differences of opinion, they discussed with the third reviewer(ZY Pan) then made arbitration and decision.

\subsection{Types of studies}

This study only included randomized controlled studies(RCTs), and there were no language restrictions. Animal studies, self-controlled studies, repeated studies, and studies where full texts were not available were excluded. Likewise, reviews articles, case reports, editorials, letters, and comments were not included.

\subsection{Inclusion Criteria}

(1)Research type: Randomized controlled trials (RCTS), whether blind or not, have no language limitations.(2)Research objects: Up to AP diagnostic criteria ${ }^{4}$.(3)Intervention measures: The control group received routine treatment, including water abstinence, fasting, gastrointestinal decompression, acid inhibition, enzyme inhibition, catharsis, pain relief, anti-infection and nutritional support, as well as symptomatic treatment such as mechanical ventilation and anti-shock when necessary. The CRRT group was treated with continuous veno-venous hemofiltration on the basis of conventional treatment. None of the patients underwent surgery.(4)Outcome measurement index: mortality rate of AP patients, serum amylase, TNF- $\alpha$, CRP,PCT, IL-6 clearance rate, liver and kidney function, APACHE II score after treatment.

\subsection{Exclusion Criteria}

Before the onset of the disease with other acute attack disease, serious cardiovascular disease, pregnancy and other serious chronic diseases or severe infection. It's not CRRT versus conventional treatment. Non- 
randomized controlled trials. Self controlled experiment. Outcome indicators do not include the above main outcome indicators.

\subsection{Data extraction}

Three authors (Ma, Pan, and Fan) independent use standard form, the following data extracted from each article: the first author's last name, year of publication, sample size, age, sex, etiology, time recorded point, the outcome indicators (CRP, Serum amylase, TNF- $\alpha$, CRP,PCT,IL-6 levels after treatment, liver and kidney function, APACHEII scores after treatment). If the raw data is not evident in the article, we will contact the author to ask whether the raw data is available. If the occasion should arise, we do not extract the data completely.

\subsection{Data analysis}

The Revman 5.3 software provided by Cochrane was used in this study. For continuous variable data, the random effects model or fixed effects model is used according to $\mathrm{I}^{2}$ of the combined total results. $\mathrm{I}^{2}$ was used to evaluate heterogeneity. We considered that when $\mathrm{I}^{2}$ is greater than $50 \%$, there is a large inter-group heterogeneity, so the random effect model was applied; when $\mathrm{I}^{2}$ is less than or equal to $50 \%$, the inter-group heterogeneity is small, so the fixed effect model can be selected. For dichotomous results, a 95\% confidence interval combined RR was used as a measure of efficacy. If the units of the variables were the same, WMD was used. Otherwise, we preferred to choice SMD.

\subsection{Subgroup analysis and sensitivity analysis}

Subgroup analysis and sensitivity analysis play an important role in order to explore the source of heterogeneity. Among them, methodology, statistics and clinical characteristics are all potential sources that may constitute heterogeneity. When there's a huge difference in the results of clinical trials and the heterogeneity is significant, we removed one trial that is significantly different from the other trials and then combined the remaining studies to compare the results before and after the trial.

\section{Results}

\subsection{Literature Search}

As shown in the flow chart in Figure 1, this study found a total of 846 relevant literatures through the database retrieval mentioned above.163 references were excluded due to duplication of content. After screening the title and abstract, 554 articles were excluded because they did not meet the eligible criteria. Then 76 articles were excluded according to the full text content, which combined with other interventions $(\mathrm{n}=30)$, review $\operatorname{articles}(\mathrm{n}=6)$, non-RCT $(\mathrm{n}=4)$, with other early acute diseases $(\mathrm{n}=31)$, full text was not available $(\mathrm{n}=5)$. Finally, a total of 53 randomized controlled trials (RCTS) (3 English ${ }^{11-13}$ and 50 Chinese $^{14-63}$ ) that met the criteria were included for meta-analysis. 


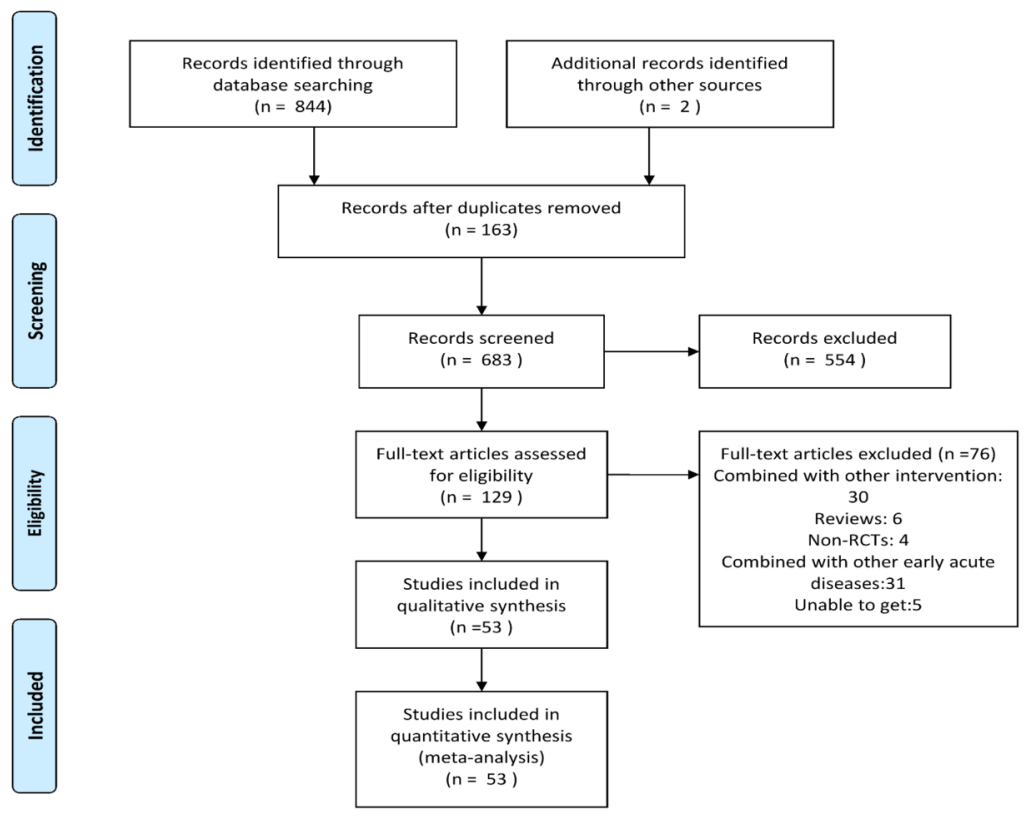

Fig. 1 Filter article flow diagram according to inclusion criteria

\subsection{Risk of bias assessment}

The quality of RCT was assessed according to the Cochrane Evaluation Manual, including six aspects: randomization, allocation concealment, blindness, incomplete data bias, selective reporting of results, and other factors that may potentially affect authenticity. If the number of people lost to follow-up exceeded $10 \%$ in the included study, the possible causes of loss of follow-up were further analyzed and intention-to-treat (ITT) analysis was performed. For each included study, 3 evaluations were made for the above 6 items, namely, low bias risk, high bias risk and unclear risk (Fig. 2). 


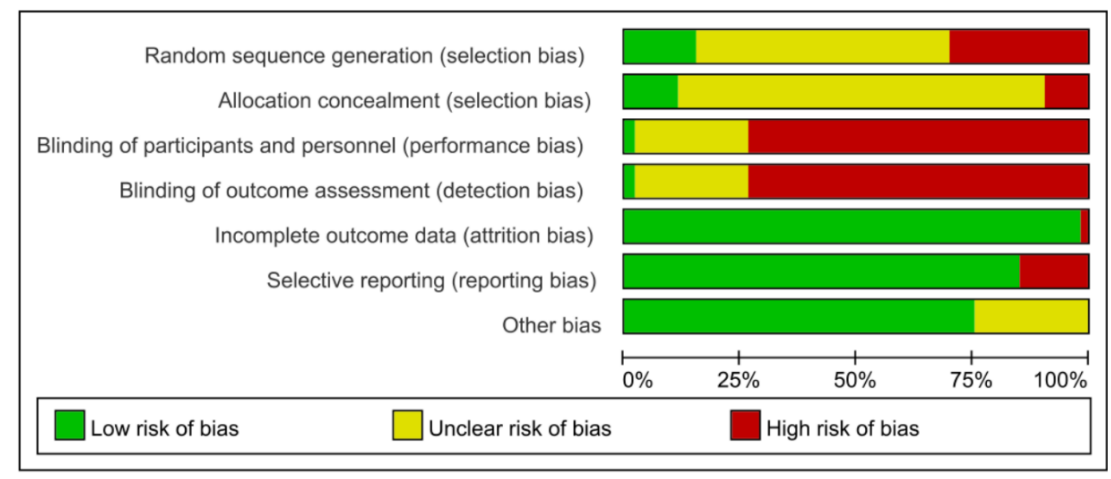

Fig.2 Assessment of the methodological quality of the included studies

\subsection{Study Characteristics}

The patient characteristics and main outcome indicators included in the included study are shown in Table 1. All the studies were published between 2001 and 2020. A total of 3382 patients were included in this study.

Table 1.Characteristics of patients with acute pancreatitis and disease causes and outcome indicators.

\begin{tabular}{|c|c|c|c|c|c|c|}
\hline Studies & $\mathrm{N}(\mathrm{T} / \mathrm{C})$ & $\begin{array}{l}\text { Gender } \\
\text { (male/female) }\end{array}$ & $\begin{array}{l}\text { Mean age } \pm \\
\text { SD (years) }\end{array}$ & $\begin{array}{l}\text { Cause of acute } \\
\text { panScreatitis }\end{array}$ & $\begin{array}{l}\text { time recorded } \\
\text { point }\end{array}$ & $\begin{array}{l}\text { outcome } \\
\text { indicators }\end{array}$ \\
\hline $\begin{array}{l}\text { Xu GB et al. } \\
2013\end{array}$ & $35 / 35$ & $37 / 33$ & $50.3 \pm 7.9$ & $\begin{array}{l}\text { biliary tract } \\
\text { diseases: } 37 \\
\text { excessive } \\
\text { drinking and } \\
\text { eating:5 } \\
\text { traumatic } \\
\text { injury:5 } \\
\text { unknown } \\
\text { cause:5 }\end{array}$ & NR & $\begin{array}{l}\text { APACHE-II } \\
\text { score,CRP,Lengt } \\
\text { of ICU stay } \\
\text { and mortality } \\
\text { rate }\end{array}$ \\
\hline $\begin{array}{l}\text { Liu XS et al. } \\
2017\end{array}$ & $22 / 53$ & $\begin{array}{l}\mathrm{T}: 14 / 8 \\
\mathrm{C}: 31 / 22\end{array}$ & $\begin{array}{l}\mathrm{T}:(52.1 \pm 11.2) \\
\mathrm{C}:(50.7+-13.4)\end{array}$ & NR & $24 \mathrm{~h} 72 \mathrm{~h}$ & $\begin{array}{l}\mathrm{HR} \text {, urine } \\
\text { volume, } \\
\mathrm{K}+, \mathrm{BUN}, \mathrm{Scr}, \mathrm{CR} \\
\alpha, \\
\text { IL-6 }\end{array}$ \\
\hline $\begin{array}{l}\text { Wang XQ et } \\
\text { al. } 2019\end{array}$ & $35 / 25$ & $\begin{array}{l}\mathrm{T}: 22 / 13 \\
\mathrm{C}: 18 / 7\end{array}$ & $\begin{array}{l}\mathrm{T}:(40.5 \pm 9.5) \\
\mathrm{C}:(41.1+-9.5)\end{array}$ & hyperlipidemia & NR & $\begin{array}{l}\text { Treatment } \\
\text { effect,TG, } \\
\text { CRP,blood } \\
\text { amylase and } \\
\text { urine amylase }\end{array}$ \\
\hline $\begin{array}{l}\text { Hui WJ et al. } \\
2017\end{array}$ & $60 / 60$ & $\begin{array}{l}\mathrm{T}: 32 / 28 \\
\mathrm{C}: 30 / 30\end{array}$ & $\begin{array}{l}\mathrm{T}:(37.6 \pm 5.4) \\
\mathrm{C}:(38.1+-5.6)\end{array}$ & NR & NR & $\begin{array}{l}\text { Treatment } \\
\text { effect, blood } \\
\text { amylase, } \\
\text { TNF- } \alpha \text {, IL-1 }\end{array}$ \\
\hline $\begin{array}{l}\text { Zou YD et al. } \\
2017\end{array}$ & $31 / 31$ & $\begin{array}{l}\mathrm{T}: 18 / 13 \\
\mathrm{C}: 16 / 15\end{array}$ & $\begin{array}{l}\mathrm{T}:(43.02 \pm 4.51) \\
\mathrm{C}:(43.85+- \\
3.91)\end{array}$ & NR & NR & $\begin{array}{l}\text { Treatment } \\
\text { effect, blood } \\
\text { amylase, CRP, } \\
\text { IL- } 6, \mathrm{PO}_{2}\end{array}$ \\
\hline
\end{tabular}




\begin{tabular}{|c|c|c|c|c|c|c|}
\hline Studies & $\mathrm{N}(\mathrm{T} / \mathrm{C})$ & $\begin{array}{l}\text { Gender } \\
\text { (male/female) }\end{array}$ & $\begin{array}{l}\text { Mean age } \pm \\
\text { SD (years) }\end{array}$ & $\begin{array}{l}\text { Cause of acute } \\
\text { panScreatitis }\end{array}$ & $\begin{array}{l}\text { time recorded } \\
\text { point }\end{array}$ & $\begin{array}{l}\text { outcome } \\
\text { indicators }\end{array}$ \\
\hline $\begin{array}{l}\text { Deng ZY et al. } \\
2014\end{array}$ & $32 / 32$ & $46 / 18$ & 41.7 & $\begin{array}{l}\text { biliary pan- } \\
\text { Screatitis:47 } \\
\text { alcoholic pan- } \\
\text { Screatitis:12 } \\
\text { unknown } \\
\text { cause:5 }\end{array}$ & NR & $\begin{array}{l}\text { APACHE-II } \\
\text { score,TNF- } \alpha \text {, } \\
\text { endotoxin, } \\
\text { IL-6, IL-18, } \\
\text { mortality rate }\end{array}$ \\
\hline $\begin{array}{l}\text { Peng Y et al. } \\
2019\end{array}$ & $22 / 20$ & $25 / 27$ & 37 & $\begin{array}{l}\text { biliary tract } \\
\text { diseases:18 } \\
\text { excessive } \\
\text { drinking and } \\
\text { eating:11 } \\
\text { mixed cause:10 } \\
\text { idiopathic } \\
\text { cause:3 }\end{array}$ & NR & $\begin{array}{l}\text { IL- } 6, \mathrm{TNF}-\alpha, \\
\text { blood amylase }\end{array}$ \\
\hline $\begin{array}{l}\text { Zhong X et al. } \\
2017\end{array}$ & $37 / 37$ & $\begin{array}{l}\mathrm{T}: 23 / 14 \\
\mathrm{C}: 21 / 16\end{array}$ & $\begin{array}{l}\mathrm{T}:(56.5 \pm 4.3) \\
\mathrm{C}:(55.8+-4.4)\end{array}$ & $\begin{array}{l}\text { T: biliary tract } \\
\text { diseases: } 14 \\
\text { excessive } \\
\text { drinking and } \\
\text { eating:8 } \\
\text { alcoholism:9 } \\
\text { other cause:6 } \\
\text { C: biliary tract } \\
\text { diseases: } 15 \\
\text { excessive } \\
\text { drinking and } \\
\text { eating:7 } \\
\text { alcoholism:8 } \\
\text { other cause:7 }\end{array}$ & $72 \mathrm{~h}$ & $\begin{array}{l}\text { Treatment } \\
\text { effect, } \\
\text { APACHE-II } \\
\text { score,ALB,ALT, } \\
24 \mathrm{~h} \text { urine } \\
\text { output } \\
\text {,BUN,Scr }\end{array}$ \\
\hline $\begin{array}{l}\text { Peng B et al. } \\
2019\end{array}$ & $41 / 41$ & $\begin{array}{l}\mathrm{T}: 27 / 14 \\
\mathrm{C}: 26 / 15\end{array}$ & $\begin{array}{l}\mathrm{T}:(43.7 \pm 8.6) \\
\mathrm{C}:(44.3+-8.5)\end{array}$ & $\begin{array}{l}\text { T: biliary tract } \\
\text { diseases:19 hy- } \\
\text { perlipidemia: } 8 \\
\text { alcoholism:10 } \\
\text { other cause: } 4 \\
\text { C: biliary tract } \\
\text { diseases:17 hy- } \\
\text { perlipidemia:9 } \\
\text { alcoholism:10 } \\
\text { other cause:5 }\end{array}$ & $6 \mathrm{~h} 12 \mathrm{~h} 24 \mathrm{~h}$ & $\begin{array}{l}\text { PCT,CRP, } \\
\text { D-dimer, } \\
\text { blood } \\
\text { lipase,blood } \\
\text { amylase,PLT }\end{array}$ \\
\hline Zou H.2018 & $22 / 15$ & $\mathrm{~T}: 20 / 2$ C:4/11 & $\begin{array}{l}\mathrm{T}:(39.23 \pm 6.36) \\
\mathrm{C}:(38.27+- \\
6.77)\end{array}$ & hyperlipidemia & $48 \mathrm{~h}$ & $\begin{array}{l}\text { Treatment ef- } \\
\text { fect,TG,TCH, } \\
\text { blood } \\
\text { lipase,blood } \\
\text { amylase,CRP,Scr }\end{array}$ \\
\hline
\end{tabular}




\begin{tabular}{|c|c|c|c|c|c|c|}
\hline Studies & $\mathrm{N}(\mathrm{T} / \mathrm{C})$ & $\begin{array}{l}\text { Gender } \\
\text { (male/female) }\end{array}$ & $\begin{array}{l}\text { Mean age } \pm \\
\text { SD (years) }\end{array}$ & $\begin{array}{l}\text { Cause of acute } \\
\text { panScreatitis }\end{array}$ & $\begin{array}{l}\text { time recorded } \\
\text { point }\end{array}$ & $\begin{array}{l}\text { outcome } \\
\text { indicators }\end{array}$ \\
\hline $\begin{array}{l}\text { Wang Y et al. } \\
2018\end{array}$ & $36 / 36$ & $\begin{array}{l}\mathrm{T}: 24 / 12 \\
\mathrm{C}: 25 / 11\end{array}$ & $\begin{array}{l}\mathrm{T}:(47.4 \pm 13.6) \\
\mathrm{C}:(46.7+-13.2)\end{array}$ & $\begin{array}{l}\text { T: biliary tract } \\
\text { diseases:19 } \\
\text { excessive } \\
\text { drinking and } \\
\text { eating:7 } \\
\text { alcoholism:10 } \\
\text { other cause:4 } \\
\text { C: biliary tract } \\
\text { diseases:11 } \\
\text { excessive } \\
\text { drinking and } \\
\text { eating:10 } \\
\text { alcoholism:6 } \\
\text { other cause: } 7\end{array}$ & $24 \mathrm{~h} 72 \mathrm{~h}$ & $\begin{array}{l}\text { CRP, PCT, } \\
\text { Scr, BUN, Ca, } \\
\text { APACHE-II } \\
\text { score }\end{array}$ \\
\hline Ni ZH.2013 & $29 / 22$ & $\begin{array}{l}\mathrm{T}: 21 / 8 \\
\mathrm{C}: 10 / 12\end{array}$ & $\begin{array}{l}\mathrm{T}:(47.3 \pm 14) \\
\mathrm{C}:(47.18+- \\
12.24)\end{array}$ & $\begin{array}{l}\text { T: biliary tract } \\
\text { diseases:8 } \\
\text { excessive } \\
\text { drinking and } \\
\text { eating:8 } \\
\text { alcoholism:8 } \\
\text { unknown } \\
\text { cause:5 C: } \\
\text { biliary tract } \\
\text { diseases:7 } \\
\text { excessive } \\
\text { drinking and } \\
\text { eating:3 } \\
\text { alcoholism:5 } \\
\text { unknown } \\
\text { cause:7 }\end{array}$ & $24 \mathrm{~h} 48 \mathrm{~h} 72 \mathrm{~h}$ & $\begin{array}{l}24 \mathrm{~h} \text { urine out- } \\
\text { put,PH,PO2,PC } \\
\text { BUN,SCr,Na,K, } \\
\text { Treatment } \\
\text { effect }\end{array}$ \\
\hline $\begin{array}{l}\text { Li YN et al. } \\
2002\end{array}$ & $20 / 17$ & $25 / 12$ & 43.3 & $\begin{array}{l}\text { biliary tract } \\
\text { diseases:7 } \\
\text { excessive } \\
\text { eating: } 6 \\
\text { alcoholism:10 } \\
\text { unknown } \\
\text { cause:3 } \\
\text { Trauma:2 }\end{array}$ & 7days & $\begin{array}{l}\text { Treatment } \\
\text { effect, blood } \\
\text { amylase,SCr,TP, }\end{array}$ \\
\hline $\begin{array}{l}\text { Chen DJ et } \\
\text { al.2018 }\end{array}$ & $49 / 49$ & $\begin{array}{l}\mathrm{T}: 26 / 23 \\
\mathrm{C}: 24 / 25\end{array}$ & $\begin{array}{l}\mathrm{T}:(45.72 \pm 6.34) \\
\mathrm{C}:(46.52+- \\
7.35)\end{array}$ & NR & $12 \mathrm{~h} 24 \mathrm{~h} 36 \mathrm{~h}$ & $\begin{array}{l}\mathrm{HR}, 24 \mathrm{~h} \text { urine } \\
\text { output, } \mathrm{PO}_{2}, \mathrm{PCC}\end{array}$ \\
\hline $\begin{array}{l}\text { Tian JX et } \\
\text { al.2015 }\end{array}$ & $60 / 60$ & $\begin{array}{l}\text { T:35/25 } \\
\text { C:36/24 }\end{array}$ & $\begin{array}{l}\mathrm{T}:(42.9 \pm 12.5) \\
\mathrm{C}:(43.8+-11.7)\end{array}$ & NR & $72 \mathrm{~h}$ & $\begin{array}{l}\text { APACHE-II } \\
\text { score, blood } \\
\text { amylase,ALB,TP }\end{array}$ \\
\hline
\end{tabular}




\begin{tabular}{|c|c|c|c|c|c|c|}
\hline Studies & $\mathrm{N}(\mathrm{T} / \mathrm{C})$ & $\begin{array}{l}\text { Gender } \\
\text { (male/female) }\end{array}$ & $\begin{array}{l}\text { Mean age } \pm \\
\text { SD (years) }\end{array}$ & $\begin{array}{l}\text { Cause of acute } \\
\text { panScreatitis }\end{array}$ & $\begin{array}{l}\text { time recorded } \\
\text { point }\end{array}$ & $\begin{array}{l}\text { outcome } \\
\text { indicators }\end{array}$ \\
\hline Li Q.2020 & $27 / 27$ & $\begin{array}{l}\mathrm{T}: 15 / 12 \\
\mathrm{C}: 14 / 13\end{array}$ & $\begin{array}{l}\mathrm{T}:(45.39 \pm 5.56) \\
\mathrm{C}:(45.66+- \\
5.79)\end{array}$ & $\begin{array}{l}\text { T: biliary } \\
\text { calculi:4 } \\
\text { alcoholism:7 } \\
\text { sphincter } \\
\text { dysfunction of } \\
\text { hepatopancre- } \\
\text { atic ampulla:3 } \\
\text { hyperlipi- } \\
\text { demia:3 } \\
\text { excessive } \\
\text { drinking and } \\
\text { eating:10 C: } \\
\text { biliary } \\
\text { calculi:3 } \\
\text { alcoholism:8 } \\
\text { sphincter } \\
\text { dysfunction of } \\
\text { hepatopancre- } \\
\text { atic ampulla:4 } \\
\text { hyperlipi- } \\
\text { demia:3 } \\
\text { excessive } \\
\text { drinking and } \\
\text { eating:9 }\end{array}$ & $72 \mathrm{~h}$ & $\begin{array}{l}\text { APACHE-II } \\
\text { score, } \\
\text { Treatment } \\
\text { effect }\end{array}$ \\
\hline Xiao XP.2014 & $17 / 13$ & $18 / 12$ & $48 \pm 5$ & NR & $24 \mathrm{~h} 48 \mathrm{~h} 72 \mathrm{~h}$ & $\begin{array}{l}\text { Treatment } \\
\text { effect,TNF- } \alpha\end{array}$ \\
\hline $\begin{array}{l}\text { Zhu JG et } \\
\text { al.2007 }\end{array}$ & $17 / 14$ & $\mathrm{~T}: 10 / 7$ C:9/5 & $\begin{array}{l}\mathrm{T}:(49.93 \pm 10.3) \\
\mathrm{C}:(51.05+- \\
11.10)\end{array}$ & NR & NR & $\begin{array}{l}\text { HR,PCT,CRP, } \\
\text { Treatment } \\
\text { effect }\end{array}$ \\
\hline Wang LY.2017 & $45 / 45$ & $\begin{array}{l}\mathrm{T}: 28 / 17 \\
\mathrm{C}: 25 / 20\end{array}$ & $\begin{array}{l}\mathrm{T}:(46.25 \pm 5.63) \\
\mathrm{C}:(48.53+- \\
6.24)\end{array}$ & NR & NR & $\begin{array}{l}\text { APACHE-II } \\
\text { score,CRP,PCT, } \\
\text { TNF- } \alpha\end{array}$ \\
\hline Yang H.2013 & $25 / 25$ & $27 / 23$ & 43.25 & NR & NR & $\begin{array}{l}\text { APACHE-II } \\
\text { score,SCr,TG, } \\
\text { blood } \\
\text { amylase } \\
\text {,PO } \mathrm{PO}_{2}, \mathrm{ALT}\end{array}$ \\
\hline Li KY.2016 & $30 / 30$ & $\begin{array}{l}\mathrm{T}: 20 / 10 \\
\mathrm{C}: 16 / 14\end{array}$ & NR & NR & $24 \mathrm{~h} 72 \mathrm{~h} 7$ days & $\begin{array}{l}\text { HR,APACHE- } \\
\text { II } \\
\text { score,CRP,PCT, } \\
\text { TNF- } \\
\alpha, B U N, S C r, A L T\end{array}$ \\
\hline
\end{tabular}




\begin{tabular}{|c|c|c|c|c|c|c|}
\hline Studies & $\mathrm{N}(\mathrm{T} / \mathrm{C})$ & $\begin{array}{l}\text { Gender } \\
\text { (male/female) }\end{array}$ & $\begin{array}{l}\text { Mean age } \pm \\
\text { SD (years) }\end{array}$ & $\begin{array}{l}\text { Cause of acute } \\
\text { panScreatitis }\end{array}$ & $\begin{array}{l}\text { time recorded } \\
\text { point }\end{array}$ & $\begin{array}{l}\text { outcome } \\
\text { indicators }\end{array}$ \\
\hline $\begin{array}{l}\text { Cui WY et } \\
\text { al.2017 }\end{array}$ & $16 / 11$ & $\mathrm{~T}: 10 / 6 \mathrm{C}: 4 / 7$ & $\begin{array}{l}\mathrm{T}:(49.91 \pm 24.23) \\
\mathrm{C}:(50.63+- \\
14.30)\end{array}$ & $\begin{array}{l}\text { T: biliary tract } \\
\text { diseases:8 } \\
\text { alcoholism:2 } \\
\text { hyperlipi- } \\
\text { demia:5 other } \\
\text { cause:1 C: } \\
\text { biliary tract } \\
\text { diseases:7 } \\
\text { alcoholism:2 } \\
\text { hyperlipi- } \\
\text { demia:2 other } \\
\text { cause:0 }\end{array}$ & $24 \mathrm{~h} 72 \mathrm{~h}$ & $\overline{\mathrm{SCr}, \mathrm{WBC}, \mathrm{CRP}}$ \\
\hline $\begin{array}{l}\text { Chen } \\
\text { FS.2020 }\end{array}$ & $45 / 45$ & $45 / 45$ & $45 \pm 6.7$ & NR & $48 \mathrm{~h}$ & $\begin{array}{l}\mathrm{SCr}, \mathrm{PCT}, \mathrm{TG}, \mathrm{TE} \\
\text { blood } \\
\text { amylase }\end{array}$ \\
\hline $\begin{array}{l}\text { Xu F et } \\
\text { al.2019 }\end{array}$ & $32 / 32$ & $\begin{array}{l}\mathrm{T}: 19 / 13 \\
\mathrm{C}: 18 / 14\end{array}$ & $\begin{array}{l}\mathrm{T}:(42.05 \pm 3.93) \\
\mathrm{C}:(42.68+- \\
2.95)\end{array}$ & $\begin{array}{l}\text { T: biliary tract } \\
\text { diseases:14 } \\
\text { alcoholism:13 } \\
\text { hyperlipi- } \\
\text { demia:5 C: } \\
\text { biliary tract } \\
\text { diseases:15 } \\
\text { alcoholism:12 } \\
\text { hyperlipidemia:5 }\end{array}$ & $72 \mathrm{~h}$ & $\begin{array}{l}\mathrm{HR}, \mathrm{BUN}, \mathrm{SCr}, \mathrm{AI} \\
\text { blood amylase }\end{array}$ \\
\hline Zhu CZ.2016 & $40 / 40$ & $\begin{array}{l}\mathrm{T}: 25 / 15 \\
\mathrm{C}: 28 / 12\end{array}$ & $\begin{array}{l}\mathrm{T}:(45.2 \pm 8.5) \\
\mathrm{C}:(44.9+-7.9)\end{array}$ & NR & $72 \mathrm{~h}$ & $\mathrm{PO}_{2}, \mathrm{PCO}_{2}, \mathrm{WBC}$ \\
\hline $\begin{array}{l}\text { Gao N. et } \\
\text { al.2018 }\end{array}$ & $46 / 46$ & $\begin{array}{l}\mathrm{T}: 24 / 22 \\
\mathrm{C}: 22 / 24\end{array}$ & $\begin{array}{l}\mathrm{T}:(38.87 \pm 6.47) \\
\mathrm{C}:(39.13+- \\
6.56)\end{array}$ & $\begin{array}{l}\text { T: } \\
\text { alcoholism:16 } \\
\text { hyperlipi- } \\
\text { demia:20 } \\
\text { cholelithiasis:7 } \\
\text { other cause:3 } \\
\text { C: } \\
\text { alcoholism:14 } \\
\text { hyperlipi- } \\
\text { demia:18 } \\
\text { cholelithiasis:9 } \\
\text { other cause:5 }\end{array}$ & $6 \mathrm{~h} 12 \mathrm{~h} 24 \mathrm{~h}$ & $\begin{array}{l}\text { PCT,CRP,IL- } \\
\text { 17,IL- } \\
6, H M G B 1, D- \\
\text { dimer }\end{array}$ \\
\hline $\begin{array}{l}\text { Xu JM. et } \\
\text { al.2017 }\end{array}$ & $25 / 11$ & $\begin{array}{l}\mathrm{T}: 24 / 22 \\
\mathrm{C}: 22 / 24\end{array}$ & NR & NR & 7 days & $\begin{array}{l}\text { blood } \\
\text { amylase,ALT,SC }\end{array}$ \\
\hline $\begin{array}{l}\text { Chen X et } \\
\text { al.2019 }\end{array}$ & $32 / 28$ & $\begin{array}{l}\text { T:20/12 } \\
\text { C:18/10 }\end{array}$ & $\begin{array}{l}\mathrm{T}:(54.32 \pm 10.65) \\
\mathrm{C}:(58.94+- \\
9.02)\end{array}$ & NR & 7 days & $\begin{array}{l}\text { ALT,AST, } \\
\text { TBIL,ALB,WBC } \\
\text { blood and } \\
\text { urine amylase }\end{array}$ \\
\hline $\begin{array}{l}\text { Zhang X.et } \\
\text { al.2016 }\end{array}$ & $8 / 14$ & $14 / 8$ & $54 \pm 14$ & NR & $48 \mathrm{~h}$ & $\begin{array}{l}\text { APACHE-II } \\
\text { score,TG,CRP, } \\
\text { Treatment } \\
\text { effect }\end{array}$ \\
\hline
\end{tabular}




\begin{tabular}{|c|c|c|c|c|c|c|}
\hline Studies & $\mathrm{N}(\mathrm{T} / \mathrm{C})$ & $\begin{array}{l}\text { Gender } \\
\text { (male/female) }\end{array}$ & $\begin{array}{l}\text { Mean age } \pm \\
\text { SD (years) }\end{array}$ & $\begin{array}{l}\text { Cause of acute } \\
\text { panScreatitis }\end{array}$ & $\begin{array}{l}\text { time recorded } \\
\text { point }\end{array}$ & $\begin{array}{l}\text { outcome } \\
\text { indicators }\end{array}$ \\
\hline Wang LF.2020 & $15 / 15$ & $\mathrm{~T}: 8 / 7$ C:7/8 & $\begin{array}{l}\mathrm{T}:(46.7 \pm 11.4) \\
\mathrm{C}:(46.8+-11.5)\end{array}$ & NR & $72 \mathrm{~h}$ & $\begin{array}{l}\mathrm{Na}, \mathrm{Ca}, \mathrm{K}, \mathrm{BUN}, \mathrm{S} \\
24 \mathrm{~h} \text { urine } \\
\text { output }\end{array}$ \\
\hline $\begin{array}{l}\text { Liu MX.et } \\
\text { al.2011 }\end{array}$ & $15 / 15$ & $10 / 16$ & $53 \pm 16$ & NR & $48 \mathrm{~h}$ & $\begin{array}{l}\text { APACHE-II } \\
\text { score,TG,CRP, } \\
\text { blood and } \\
\text { urine } \\
\text { amylase, } \\
\text { Treatment } \\
\text { effect }\end{array}$ \\
\hline Xu JY.2013 & $12 / 20$ & $23 / 9$ & 47.5 & hyperlipidemia & $48 \mathrm{~h}$ & $\begin{array}{l}\text { Treatment } \\
\text { effect, } \\
\text { APACHE-II } \\
\text { score,TG,CRP,bl } \\
\text { and urine } \\
\text { amylase }\end{array}$ \\
\hline Wu SK.2015 & $28 / 30$ & $\begin{array}{l}\mathrm{T}: 18 / 10 \\
\mathrm{C}: 19 / 11\end{array}$ & $\begin{array}{l}\mathrm{T}:(67.5 \pm 10.3) \\
\mathrm{C}:(69.5+-11.3)\end{array}$ & $\begin{array}{l}\mathrm{T}: \\
\text { alcoholism:8 } \\
\text { cholelithia- } \\
\text { sis:10 other } \\
\text { cause:10 C: } \\
\text { alcoholism:10 } \\
\text { cholelithia- } \\
\text { sis:12 other } \\
\text { cause:8 }\end{array}$ & NR & $\begin{array}{l}\text { Treatment } \\
\text { effect, the time } \\
\text { taken for } \\
\text { clinical } \\
\text { indicators to } \\
\text { return to } \\
\text { normal }\end{array}$ \\
\hline $\begin{array}{l}\text { Xu Y.et } \\
\text { al.2009 }\end{array}$ & $30 / 30$ & $\begin{array}{l}\mathrm{T}: 20 / 10 \\
\mathrm{C}: 19 / 11\end{array}$ & $\begin{array}{l}\mathrm{T}:(30 \pm 10.5) \\
\mathrm{C}:(43.1+-10.5)\end{array}$ & $\begin{array}{l}\text { T: } \\
\text { alcoholism:6 } \\
\text { high-fat diet:6 } \\
\text { history of } \\
\text { biliary tract } \\
\text { infection:5 } \\
\text { excessive } \\
\text { drinking and } \\
\text { eating:12 } \\
\text { unknown } \\
\text { cause:1 C: } \\
\text { alcoholism:6 } \\
\text { high-fat diet:5 } \\
\text { history of } \\
\text { biliary tract } \\
\text { infection:8 } \\
\text { excessive } \\
\text { drinking and } \\
\text { eating:9 } \\
\text { unknown } \\
\text { cause:2 }\end{array}$ & $24 \mathrm{~h} 48 \mathrm{~h} 72 \mathrm{~h}$ & $\begin{array}{l}\text { APACHE-II } \\
\text { score }\end{array}$ \\
\hline Wei R.2016 & $40 / 40$ & NR & $60.3 \pm 1.8$ & $\begin{array}{l}\text { alcoholism: } 37 \\
\text { cholelithiasis:43 }\end{array}$ & NR & $\begin{array}{l}\text { APACHE-II } \\
\text { score,HR,MAP,C }\end{array}$ \\
\hline
\end{tabular}




\begin{tabular}{|c|c|c|c|c|c|c|}
\hline Studies & $\mathrm{N}(\mathrm{T} / \mathrm{C})$ & $\begin{array}{l}\text { Gender } \\
\text { (male/female) }\end{array}$ & $\begin{array}{l}\text { Mean age } \pm \\
\text { SD (years) }\end{array}$ & $\begin{array}{l}\text { Cause of acute } \\
\text { panScreatitis }\end{array}$ & $\begin{array}{l}\text { time recorded } \\
\text { point }\end{array}$ & $\begin{array}{l}\text { outcome } \\
\text { indicators }\end{array}$ \\
\hline Tian GX.2016 & $60 / 60$ & $\begin{array}{l}\mathrm{T}: 32 / 28 \\
\mathrm{C}: 30 / 30\end{array}$ & $\begin{array}{l}\mathrm{T}:(37.6 \pm 5.4) \\
\mathrm{C}:(38.1+-5.6)\end{array}$ & $\mathrm{NR}$ & $\mathrm{NR}$ & $\begin{array}{l}\text { Treatment } \\
\text { effect,IL- } \\
1, \mathrm{TNF}-\alpha, \text { blood } \\
\text { amylase }\end{array}$ \\
\hline Wan CS.2017 & $60 / 60$ & NR & NR & $\begin{array}{l}\text { T: } \\
\text { alcoholism:18 } \\
\text { cholelithia- } \\
\text { sis:13 excessive } \\
\text { drinking and } \\
\text { eating:24 } \\
\text { unknown } \\
\text { cause:5 C: } \\
\text { alcoholism:20 } \\
\text { cholelithia- } \\
\text { sis:15 excessive } \\
\text { drinking and } \\
\text { eating:21 } \\
\text { unknown } \\
\text { cause: } 4\end{array}$ & $72 \mathrm{~h}$ & $\begin{array}{l}\mathrm{Na}, \mathrm{K}, \mathrm{Ca}, \mathrm{BUN}, \mathrm{SC} \\
24 \mathrm{~h} \text { urine } \\
\text { output }\end{array}$ \\
\hline $\begin{array}{l}\text { Wang YF.et } \\
\text { al.2017 }\end{array}$ & $12 / 20$ & $\mathrm{~T}: 7 / 5 \mathrm{C}: 14 / 6$ & $\mathrm{~T}: 42 \mathrm{C}: 41$ & hyperlipidemia & NR & $\begin{array}{l}\text { HR,SCr,TG,CRP } \\
1, \mathrm{TNF}-\alpha, \mathrm{GLU}, \\
\text { APACHE-II } \\
\text { score }\end{array}$ \\
\hline $\begin{array}{l}\text { Ji HL.et } \\
\text { al.2011 }\end{array}$ & $36 / 38$ & $\begin{array}{l}\mathrm{T}: 23 / 13 \\
\mathrm{C}: 25 / 13\end{array}$ & T:57 C:54 & NR & NR & $\begin{array}{l}\text { CRP,APN, } \\
\text { Treatment } \\
\text { effect }\end{array}$ \\
\hline Li LL.2018 & $40 / 40$ & $\begin{array}{l}\mathrm{T}: 23 / 17 \\
\mathrm{C}: 25 / 15\end{array}$ & $\begin{array}{l}\mathrm{T}:(43.26 \pm 8.87) \\
\mathrm{C}:(42.17+- \\
8.67)\end{array}$ & NR & $72 \mathrm{~h}$ & $\begin{array}{l}\text { IL- } \\
6, \mathrm{TNF} \alpha, \mathrm{SCr}, \mathrm{BUN} \\
\text { Treatment } \\
\text { effect }\end{array}$ \\
\hline Li YP.2014 & $13 / 13$ & $\mathrm{~T}: 9 / 4 \mathrm{C}: 9 / 4$ & T:51.8 C:56.5 & $\begin{array}{l}\text { alcoholism:8 } \\
\text { cholelithiasis:3 } \\
\text { excessive } \\
\text { drinking and } \\
\text { eating:10 hy- } \\
\text { perlipidemia:2 } \\
\text { surgery:1 hep- } \\
\text { atopancreatic } \\
\text { ampulla } \\
\text { sphincter } \\
\text { dysfunction:2 }\end{array}$ & 7days & $\begin{array}{l}\text { IL-6,TNF- } \\
\alpha, \mathrm{WBC}, \mathrm{HR}, \mathrm{CRP} \text {, } \\
\text {,Treatment } \\
\text { effect }\end{array}$ \\
\hline
\end{tabular}




\begin{tabular}{|c|c|c|c|c|c|c|}
\hline Studies & $\mathrm{N}(\mathrm{T} / \mathrm{C})$ & $\begin{array}{l}\text { Gender } \\
\text { (male/female) }\end{array}$ & $\begin{array}{l}\text { Mean age } \pm \\
\text { SD (years) }\end{array}$ & $\begin{array}{l}\text { Cause of acute } \\
\text { panScreatitis }\end{array}$ & $\begin{array}{l}\text { time recorded } \\
\text { point }\end{array}$ & $\begin{array}{l}\text { outcome } \\
\text { indicators }\end{array}$ \\
\hline $\begin{array}{l}\text { Li QB.et } \\
\text { al.2009 }\end{array}$ & $19 / 19$ & $\mathrm{~T}: 12 / 7 \mathrm{C}: 14 / 5$ & $\begin{array}{l}\mathrm{T}:(44.3 \pm 19.5) \\
\mathrm{C}:(45.4+-18.7)\end{array}$ & $\begin{array}{l}\text { T: cholelithia- } \\
\text { sis:10 excessive } \\
\text { drinking and } \\
\text { eating:5 } \\
\text { trauma:2 } \\
\text { unknown } \\
\text { cause:2 C: } \\
\text { cholelithia- } \\
\text { sis:13 excessive } \\
\text { drinking and } \\
\text { eating:6 }\end{array}$ & $72 \mathrm{~h}$ & $\begin{array}{l}\text { IL-6,TNF- } \alpha \text {, } \\
\text { APACHE-II } \\
\text { score, } \mathrm{PO}_{2}, \mathrm{PH} \text {, } \\
\text { Treatment } \\
\text { effect }\end{array}$ \\
\hline $\begin{array}{l}\mathrm{Hu} \text { W.et } \\
\text { al.2001 }\end{array}$ & $10 / 10$ & $\mathrm{~T}: 7 / 3 \mathrm{C}: 7 / 3$ & $\begin{array}{l}\mathrm{T}:(56.8 \pm 15.4) \\
\mathrm{C}:(59.7+-13.2)\end{array}$ & NR & 7days & $\begin{array}{l}\text { IL-6,TNF- } \\
\alpha, \text { IL- } \\
1 \beta, \text { APACHE- } \\
\text { II } \\
\text { score,Treatment } \\
\text { effect }\end{array}$ \\
\hline $\begin{array}{l}\text { Shen Q.et } \\
\text { al. } 2016\end{array}$ & $43 / 35$ & $47 / 31$ & $47.3 \pm 14.8$ & $\begin{array}{l}\text { cholelithiasis:23 } \\
\text { excessive } \\
\text { drinking and } \\
\text { eating:13 } \\
\text { alcoholism:18 } \\
\text { hyperlipi- } \\
\text { demia:15 } \\
\text { unknown } \\
\text { cause:9 }\end{array}$ & $72 \mathrm{~h}$ & $\begin{array}{l}\text { APACHE-II } \\
\text { score, } \\
\text { TNF- } \alpha, \mathrm{CRP}, \\
\text { Treatment } \\
\text { effect, blood } \\
\text { amylase }\end{array}$ \\
\hline $\begin{array}{l}\text { Sun JH.et } \\
\text { al. } 2018\end{array}$ & $39 / 39$ & $\begin{array}{l}\mathrm{T}: 22 / 17 \\
\mathrm{C}: 24 / 15\end{array}$ & $\begin{array}{l}\mathrm{T}:(40.4 \pm 5.9) \\
\mathrm{C}:(43.6+-6.9)\end{array}$ & NR & $24 \mathrm{~h}$ & $\begin{array}{l}\text { HR,BUN,SCr,AL } \\
\text { blood amylase }\end{array}$ \\
\hline $\begin{array}{l}\text { Wu LM.et } \\
\text { al. } 2013\end{array}$ & $40 / 18$ & $\begin{array}{l}\mathrm{T}: 17 / 23 \\
\mathrm{C}: 11 / 7\end{array}$ & $\begin{array}{l}\mathrm{T}:(50.5 \pm 9.4) \\
\mathrm{C}:(51.4+-7.8)\end{array}$ & $\begin{array}{l}\text { cholelithiasis: } 43 \\
\text { hyperlipi- } \\
\text { demia: } 13 \text { other } \\
\text { cause: } 2\end{array}$ & $72 \mathrm{~h}$ & $\begin{array}{l}\text { APACHE-II } \\
\text { score,TBIL,SCr, }\end{array}$ \\
\hline Liu JQ.2019 & $50 / 50$ & $\begin{array}{l}\mathrm{T}: 27 / 23 \\
\mathrm{C}: 26 / 24\end{array}$ & $\begin{array}{l}\mathrm{T}:(42.3 \pm 6.5) \\
\mathrm{C}:(42.1+-7.1)\end{array}$ & $\begin{array}{l}\text { T: cholelithia- } \\
\text { sis:11 } \\
\text { hyperlipi- } \\
\text { demia:17 } \\
\text { alcohol } \\
\text { abuse:14 other } \\
\text { cause:8 C: } \\
\text { cholelithia- } \\
\text { sis:13 } \\
\text { hyperlipi- } \\
\text { demia:15 } \\
\text { alcohol } \\
\text { abuse:16 other } \\
\text { cause:6 }\end{array}$ & $72 \mathrm{~h}$ & $\mathrm{PO}_{2}, \mathrm{WBC}, \mathrm{MAP}$ \\
\hline $\begin{array}{l}\text { Hou QC.et } \\
\text { al.2018 }\end{array}$ & $36 / 36$ & $\begin{array}{l}\mathrm{T}: 20 / 18 \\
\mathrm{C}: 22 / 16\end{array}$ & $\begin{array}{l}\mathrm{T}:(42.3 \pm 6.5) \\
\mathrm{C}:(45.6+-3.6)\end{array}$ & NR & NR & $\begin{array}{l}\text { APACHE-II } \\
\text { score,CRP,PCT, } \\
\alpha\end{array}$ \\
\hline
\end{tabular}




\begin{tabular}{|c|c|c|c|c|c|c|}
\hline Studies & $\mathrm{N}(\mathrm{T} / \mathrm{C})$ & $\begin{array}{l}\text { Gender } \\
\text { (male/female) }\end{array}$ & $\begin{array}{l}\text { Mean age } \pm \\
\text { SD (years) }\end{array}$ & $\begin{array}{l}\text { Cause of acute } \\
\text { panScreatitis }\end{array}$ & $\begin{array}{l}\text { time recorded } \\
\text { point }\end{array}$ & $\begin{array}{l}\text { outcome } \\
\text { indicators }\end{array}$ \\
\hline Zhou JY.2015 & $23 / 23$ & $\begin{array}{l}\mathrm{T}: 13 / 10 \\
\mathrm{C}: 12 / 11\end{array}$ & $\begin{array}{l}\mathrm{T}:(46.7 \pm 8.7) \\
\mathrm{C}:(47.2+-9.1)\end{array}$ & $\begin{array}{l}\text { T: cholelithia- } \\
\text { sis: } 12 \\
\text { hyperlipi- } \\
\text { demia:4 } \\
\text { alcohol } \\
\text { abuse:6 other } \\
\text { cause:1 C: } \\
\text { cholelithia- } \\
\text { sis:10 } \\
\text { hyperlipi- } \\
\text { demia:4 } \\
\text { alcohol } \\
\text { abuse:7 other } \\
\text { cause:2 }\end{array}$ & NR & CRP,PCT,SCr,B \\
\hline $\begin{array}{l}\text { Yu ZD.et } \\
\text { al.2015 }\end{array}$ & . & $\begin{array}{l}\mathrm{T}: 18 / 7 \\
\mathrm{C}: 12 / 13\end{array}$ & $\mathrm{NR}$ & $\begin{array}{l}\text { biliary tract } \\
: 25 \\
\text { cholelithiasis } \\
\text { with } \\
\text { cholecystitis:10 } \\
\text { high-fat diet:7 } \\
\text { alcohol } \\
\text { abuse:3 } \\
\text { overeating:3 } \\
\text { unknown } \\
\text { cause:2 }\end{array}$ & NR & $\begin{array}{l}\text { APACHE-II } \\
\text { score,CRP }\end{array}$ \\
\hline $\begin{array}{l}\text { Wang } \\
\text { XM.2016 }\end{array}$ & $50 / 50$ & $\begin{array}{l}\mathrm{T}: 28 / 22 \\
\mathrm{C}: 26 / 24\end{array}$ & $\begin{array}{l}\mathrm{T}:(48.5 \pm 8.4) \\
\mathrm{C}:(45.4+-6.2)\end{array}$ & NR & NR & $\mathrm{PO}_{2}, \mathrm{PH}$ \\
\hline $\begin{array}{l}\text { Tang W.et } \\
\text { al.2017 }\end{array}$ & $35 / 35$ & $\begin{array}{l}\mathrm{T}: 21 / 14 \\
\mathrm{C}: 20 / 15\end{array}$ & $\begin{array}{l}\mathrm{T}:(45.6 \pm 13.1) \\
\mathrm{C}:(46.7+-12.9)\end{array}$ & $\begin{array}{l}\text { T: } \\
\text { alcoholism:8 } \\
\text { cholelithiasis:7 } \\
\text { excessive } \\
\text { drinking and } \\
\text { eating:6 hyper- } \\
\text { lipidemia:6 } \\
\text { hepatopancre- } \\
\text { atic ampulla } \\
\text { sphincter } \\
\text { dysfunction:8 } \\
\text { C: } \\
\text { alcoholism:5 } \\
\text { cholelithiasis:9 } \\
\text { excessive } \\
\text { drinking and } \\
\text { eating:6 hyper- } \\
\text { lipidemia:7 } \\
\text { hepatopancre- } \\
\text { atic ampulla } \\
\text { sphincter } \\
\text { dysfunction:8 }\end{array}$ & $48 \mathrm{~h}$ & TG,TB,SCr,PCT \\
\hline
\end{tabular}




\begin{tabular}{|c|c|c|c|c|c|c|}
\hline Studies & $\mathrm{N}(\mathrm{T} / \mathrm{C})$ & $\begin{array}{l}\text { Gender } \\
\text { (male/female) }\end{array}$ & $\begin{array}{l}\text { Mean age } \pm \\
\text { SD (years) }\end{array}$ & $\begin{array}{l}\text { Cause of acute } \\
\text { panScreatitis }\end{array}$ & $\begin{array}{l}\text { time recorded } \\
\text { point }\end{array}$ & $\begin{array}{l}\text { outcome } \\
\text { indicators }\end{array}$ \\
\hline $\begin{array}{l}\text { Peng Y.et } \\
\text { al. } 2017\end{array}$ & $40 / 40$ & $48 / 32$ & 34 & NR & NR & $\begin{array}{l}\text { Il-1 } \beta, \text { TNF- } \\
\alpha, \mathrm{PCT}, \mathrm{AMS}, \mathrm{HR} \\
\text { APACHE-II } \\
\text { score, } \\
\text { Treatment } \\
\text { effect }\end{array}$ \\
\hline
\end{tabular}

\subsection{Meta-Analysis of Outcomes Measured}

\subsubsection{Mortality rate}

Nineteen studies were included, which including 1070 patients, with 542 in the CRRT group and 528 in the control group. There was no statistical heterogeneity among the studies. The fixed effect model was used to combine the effect sizes. The results showed that the mortality rate of the CRRT group was significantly lower than that of the control group, and the difference was statistically significant $(\mathrm{RR}=0.44,95 \% \mathrm{CI} 0.34$ to $0.57, \mathrm{P}<0.000001)$ (Fig.3).

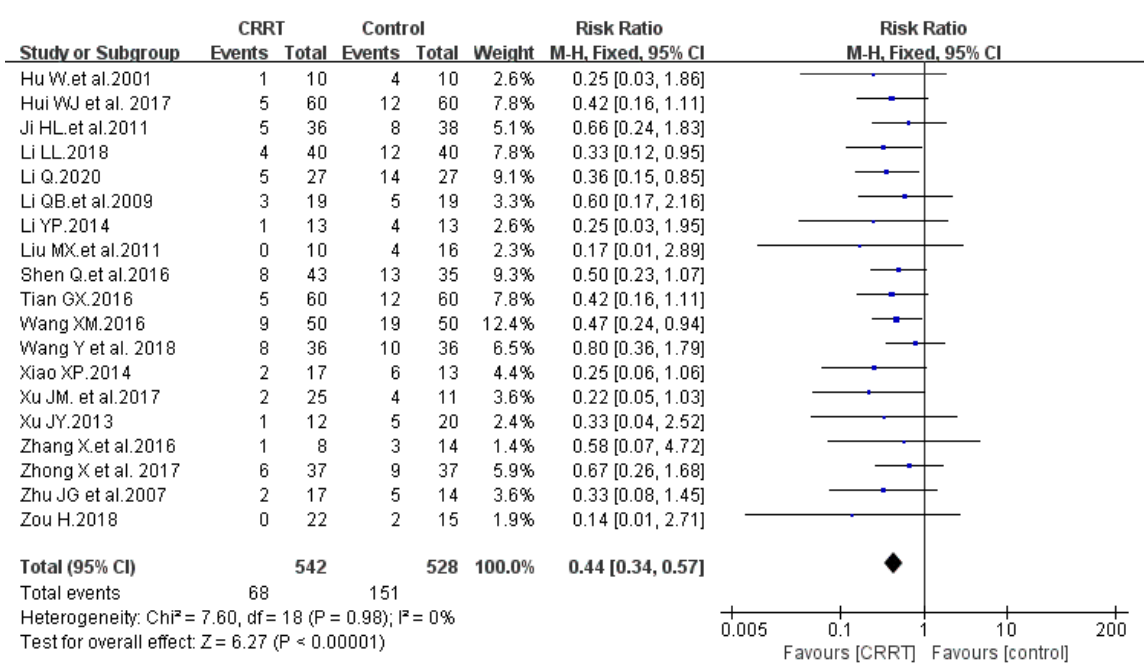

Fig.3 Comparison of forest plot of overall mortality rate between CRRT and control groups

\subsubsection{APACHEIIscores}

Twenty-one studies compared the impact of CRRT group and control group on APACHE II scores. Due to large heterogeneity $\left(\mathrm{I}^{2}=91 \%\right)$, random effects model was used for analysis, and the results showed that the difference was statistically significant $(\mathrm{WMD}=-4.20,95 \% \mathrm{CI}-4.81$ to $-3.58, \mathrm{P}<0.00001)$ ( Fig.4). Patients treated with CRRT had lower APACHE II scores than those in the control treatment group. Because APACHE II is a score that reflects the severity of a patient's illness, patients with a score greater than 15 are often considered as critical in ICU. Therefore, we conducted a subgroup analysis of the included studies based on the size of APACHE II after intervention, with the boundary of 15. Based on sensitivity analysis, the results of Wang Y, Yu DZ and Li Q crossed the invalid line and were obviously inconsistent with other research trends, therefore the three studies were excluded. $\mathrm{I}^{2}$ went from $91 \%$ to $76 \%$. 


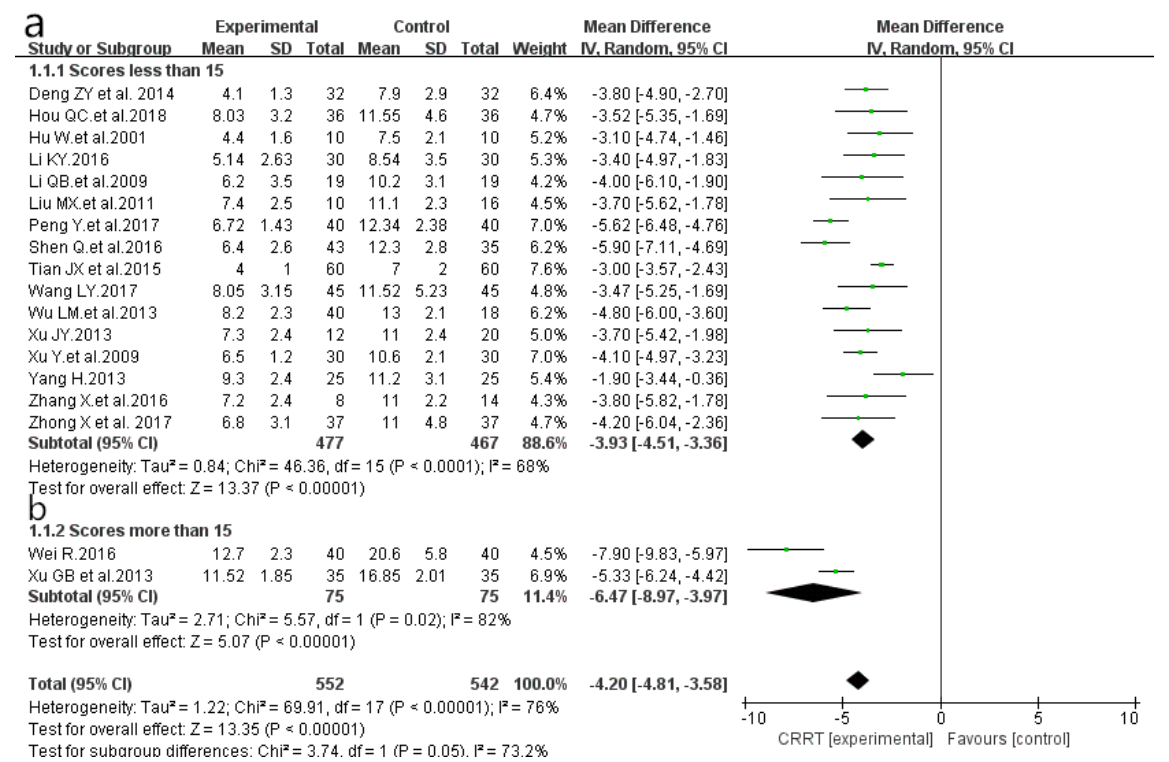

Fig.4 Comparison of forest plot of APACHEII score between CRRT and control groups. (a)The scores of the first group were less than 15 in two groups. (b)The scores of the contorl group were more than 15.

\subsubsection{CRP clearance effect}

Twenty-one studies compared the impact of CRRT group and control group on CRP clearance effect. Due to large heterogeneity $\left(\mathrm{I}^{2}=96.4 \%\right)$, random effects model was used for analysis, and the results showed that the difference was statistically significant, that compared with the control treatment group, patients treated with CRRT had significantly higher CRP clearance effect. (WMD=-8.25, 95\%CI-9.74 to -6.76, P<0.00001)(Fig.5). We conducted a subgroup analysis according to the clinical CRP value, and divided the CRP value 1-5 into a group, which was the normal value. CRP values of 5-50 were divided into a group, indicating the presence of mild and moderate inflammation in the body. CRP above 50 was divided into a group, suggesting severe inflammation in the body. 


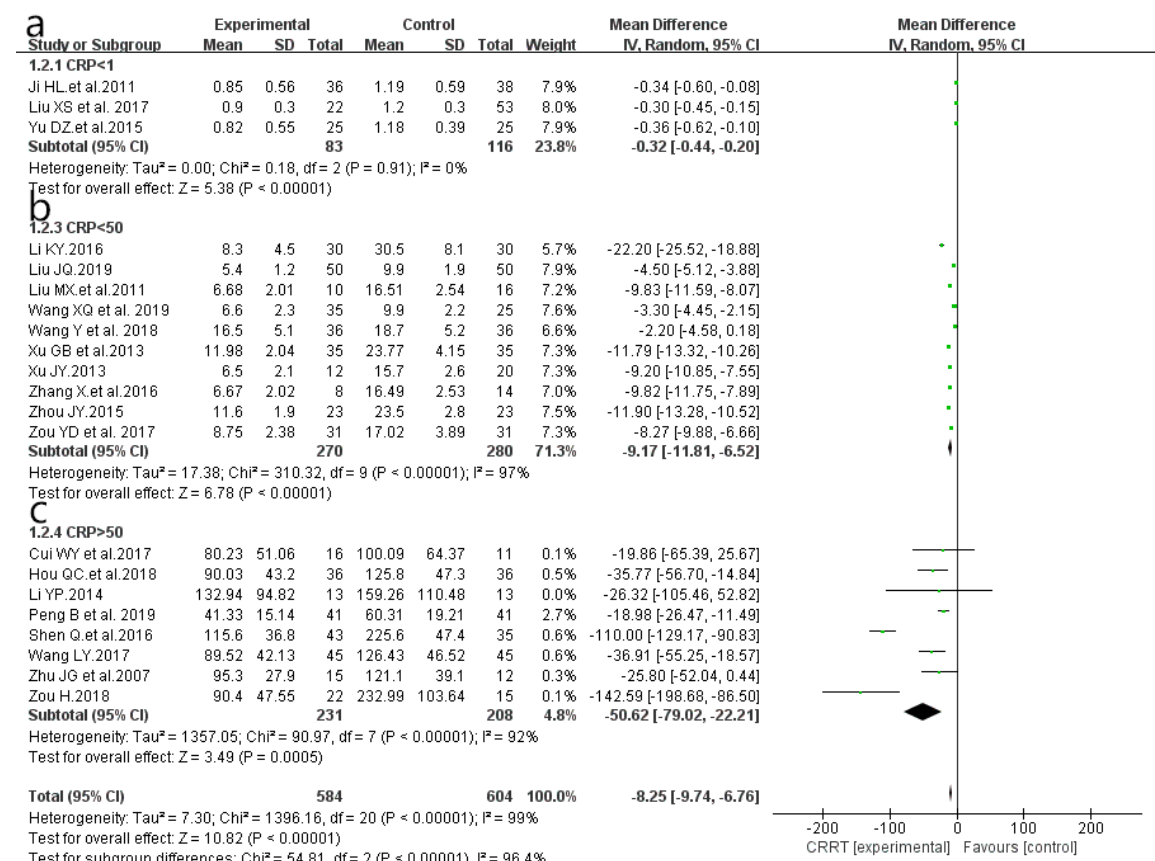

Fig.5 Comparison of forest plot of CRP clearance effect between CRRT and control groups. (a) After intervention, CRP clearance effect was below 5 in both groups. (b)CRP clearance effect was between 5 and 50 in two groups. (c)CRP clearance effect was greater than 50 in two groups.

\subsubsection{ALB level}

Six studies reported changes in ALB, there was no heterogeneity between the two groups, so the fixed-effect model was adopted. The results showed that there was a statistically significant difference between the two groups. (WMD=2.32, 95\% CI-1.05 to $3.59, \mathrm{P}=0.0003$ ) (Fig.6)

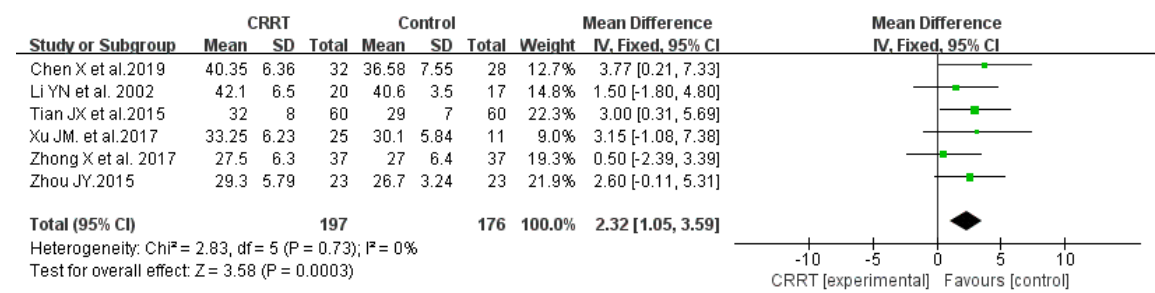

Fig.6 Comparison of forest plot of ALB level between CRRT and control groups.

\subsubsection{Renal function}

There were 19 studies comparing serum creatinine level(Fig.7) in the CRRT combination control group. Due to heterogeneity $\left(\mathrm{I}^{2}>90 \%\right)$, random effect model analysis was used, and the difference between the two groups was statistically significant $(\mathrm{WMD}=-95.59,95 \% \mathrm{CI}-126.71$ to $-64.46, \mathrm{P}<0.00001)$. Based on the subgroup analysis of whether the Scr was greater than 95 clinically, we concluded that the CRRT group presented a more significant degree of decreased creatinine value regardless of whether the patients' creatinine value was normal after treatment. However, there was great heterogeneity. After analyzing factors such as age, gender and treatment time, $\mathrm{I}^{2}$ was more than $70 \%$. So the inter-group heterogeneity of the two indicators was considered to be clinically possible. 


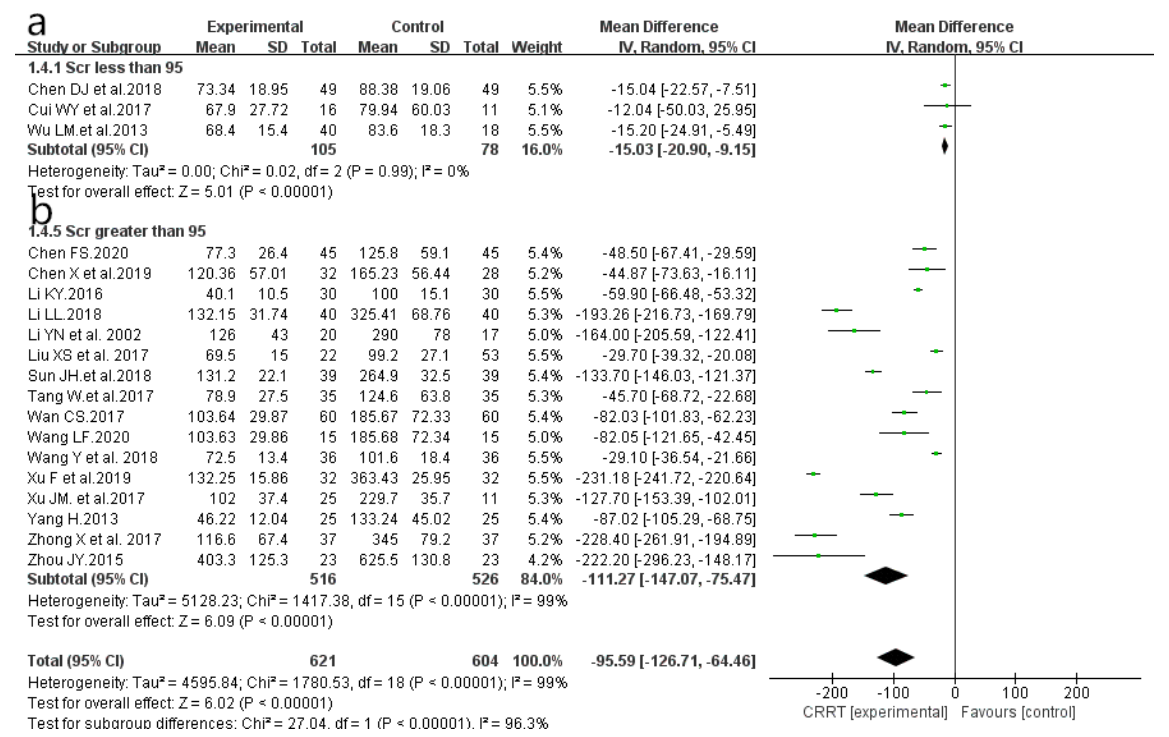

Fig.7 Comparison of forest plot of SCr level between CRRT and control groups. (a)The SCr level of two groups was less than 95. (b)The SCr level of control groups was greater than 100 .

\subsubsection{Serum potassium level}

Six studies reported changes in serum potassium, but the results showed no statistically significant difference between the two groups. (WMD $=-0.00,95 \%$ CI-0.31 to $\left.0.31, \mathrm{I}^{2}=89 \%, \mathrm{P}=1.00\right)($ Fig. 8 )

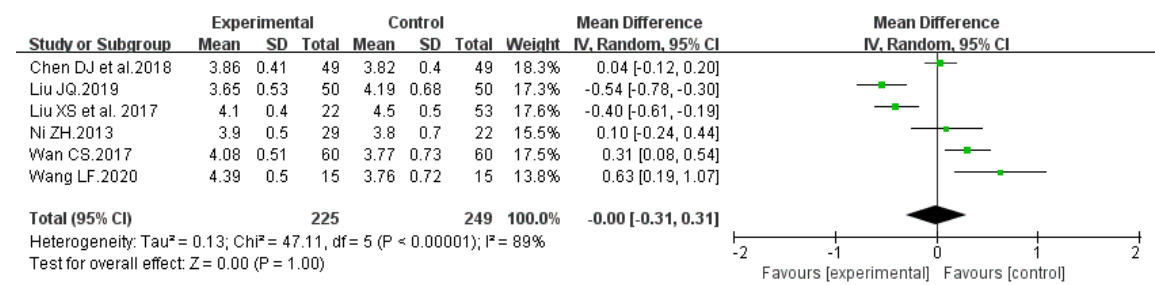

Fig.8 Comparison of forest plot of Serum potassium level between CRRT and control groups.

\subsubsection{Other outcome measures}

Nineteen studies analyzed the clearance effect of serum amylase in the CRRT group and the control group, and the heterogeneity was large $\left(\mathrm{I}^{2}>95 \%\right)$. There were respectively 9 and 15 studies compared the impact of CRRT group and control group on IL- 6 and TNF- $\alpha$ clearance effect. In the same way, both outcomes have the large heterogeneity $\left(\mathrm{I}^{2}>95 \%\right)$. We attempted to conduct a subgroup analysis of each study by age, population and the treatment time, but the results showed that there was great heterogeneity between groups, all of which exceeded $90 \%$. Therefore, we considered that the main source of heterogeneity may was clinical heterogeneity. For this reason, we conducted a systematic evaluation of the above outcome indicators, the results showed that the application of CRRT was superior to the conventional treatment in reducing the level of inflammatory factors in patients. Among them, in terms of IL-6 clearance, all the studies after CRRT were controlled below 140, while 5 studies with conventional treatment were above 200. In terms of TNF- $\alpha$ clearance effect, 6 studies were reduced to less than 50 and 12 to less than 100 after CRRT treatment, while only 2 were reduced to less than 50 and 6 were reduced to less than 100 in the conventional group. The difference between the two groups was statistically significant $(\mathrm{P}<0.00001)$. 
Similarly for serum amylase, 11 of the patients in the CRRT group had serum amylase levels below 200 after treatment, compared with only 1 in the conventional treatment group. In terms of safety, ALT levels were analyzed 11 studies, patients in the CRRT treatment group had AST over 40 in 6 studies and over 40 in 9 studies in the conventional group. The difference between the two groups was statistically significant $(\mathrm{P}<0.00001)$.

\section{Discussion}

Due to pancreatic and extra-pancreatic necrosis, acute pancreatitis (AP) is largely secondary to infection and causes Multiple organ dysfunction syndrome (MODS), which is a inflammatory disease with high morbidity and mortality ${ }^{64}$. Researchs have shown that during the pathogenesis of AP, neutrophils, lymphocytes, monocytes, natural killer cells and endothelial cells can produce a variety of cytokines or inflammatory mediators such as TNF- $\alpha$, IL-1 and IL-6, and then induce inflammatory response or reduce cellular immune response through various pathways ${ }^{65}$. Early treatment in intensive care units has been recognized to be of great benefit to patients with severe episodes. Patients with AP are generally divided into three subgroups: mild, moderate, and severe. It is necessary to adjust the treatment regimen according to their specific needs, but determining the severity of the disease remains a clinical challenge. Serum markers are generally regarded as important indicators to predict the severity of AP. Serum C-reactive protein (CRP) is an acute phase reactant synthesized by the liver. In response to inflammation and infection, its levels in the blood increase within hours. Especially in inflammatory diseases, it is often used in infection and inflammation follow-up due to its short half-life, easy measurement and close relationship with prognosis of the disease ${ }^{66}$. In many textbooks, CRP is still considered as a gold standard for disease severity assessment ${ }^{67}$. Studies have reported that low serum albumin is independently associated with an increased risk of persistent organ failure and death in acute pancreatitis and can be used to predict the severity of acute pancreatitis ${ }^{68}$.

Continuous renal replacement therapy (CRRT) is defined as a blood purification treatment technique that continuously and slowly removes water and solutes by means of extracorporeal circulation blood purification to replace renal function. Compared with common hemodialysis, CRRT can prolong the treatment time of blood purification and reduce the treatment efficiency per unit time, so as to minimize the impact of changes in the concentration and volume of solute in blood on the body. Meanwhile, it adopts a filter with high permeability and good biocompatibility. It provides an important homeostasis balance for the treatment of severe patients. With the continuous development of science and technology, CRRT has new functions in addition to regulating water and electrolyte, maintaining acid-base balance and removing metabolic wastes ${ }^{69}$. Its application scope is no longer limited to kidney disease, and began to be used in the treatment of nonrenal failure diseases such as pancreatitis ${ }^{13}$.Early CRRT can reduce the fatality rate of AP patients, as early as 2006 JPN Guideline wrote CRRT into the treatment of $\mathrm{AP}^{70}$. Researches have shown that CRRT can effectively remove the components of damaged vascular endothelial cells, improve endothelial cell function, thus reducing the incidence of MODS, and can delay or even block the process of MODS ${ }^{71}$.

This meta-analysis, which was based on 53 RCTs including 3382 participants, found that CRRT may indeed more beneficial to AP patients than conventional treatment. The study showed that after CRRT treatment, the mortality rate of the CRRT group was significantly lower than that of the control group, and there was no obvious heterogeneity between the groups, and the difference was statistically significant. CRRT also significantly reduced the APACHEIIscores and cleared serum amylase and markers of the patients, and was superior in inflammatory factor clearance rate, alleviate the liver and kidney injury and without significant adverse reactions. According to the data of each research scope is different, we carried out subgroup analysis for serum inflammatory markers, liver and kidney function, APACHE II scores. We found that there was less heterogeneity within the subgroup (less than 50\%) after grouping according to data range, but greater heterogeneity $(90 \%)$ between groups as a whole. However, there were statistically significant differences in the results, shown the efficacy of CRRT treatment was better. Therefore, we believe that the inter-group heterogeneity is mainly due to clinical heterogeneity, that is, the severity of AP patients in different studies is different, so that the datas of outcome indicators is different.

The difference between the meta-analysis in our study and the previous meta-analysis are the following : First 
of all, our study covered a large number of RCT studies and was not limited by language. A total of 3,392 subjects were included, with a larger sample size. Secondly, despite the past research done on meta-analysis of CRRT treatment of acute pancreatitis, but does not involve that much serum markers of inflammation factors and discuss the effects on liver and kidney function. As an updated and more comprehensive metaanalysis, this study further strengthened previous meta-analysis results, focused on more representative and specific results, fully described the impact of CRRT on AP patients, and strengthened the persuadability of existing evidence. Third, we registered the agreement of this study with PROSPERO in order to enhance PROSPERO's transparency and quality of this meta-analysis.

From the perspective of the included literature content, the original research has several limitations due to the defects in design, measurement and evaluation. First of all, the randomized controlled trials included in this meta-analysis were conducted in different patient groups and in different clinical Settings. Therefore, potential heterogeneity risk exists. Secondly, although baseline status was compared between groups in each study, due to the different degree of AP patients included in the meta-analysis, the baseline status varied widely from study to study, various outcome indicators in different studies may also be different, which is also considered as the main source of heterogeneity in some outcome indicators. Thirdly, since CRRT treatment is significantly different from conventional treatment, doctors and patients cannot be blinded, which may cause performance bias and observation bias. Fourthly, due to the different conditions of different patients and the different time of CRRT treatment, the experimental results may be affected. Finally, the causes of these AP patients are different, and the description of whether they have diabetes, hypertension and other underlying diseases is not detailed.

\section{Conclusions}

In conclusion, our study shows that compared with traditional treatment methods, CRRT treatment can significantly reduce the level of blood amylase, clear inflammatory mediators more significantly, reduce the score of APACHEII, slow alleviate the liver and kidney injury of patients, increase serum albumin, and reduce the mortality of AP patients. In order to confirm the reliability of the results of this study, we hope that more high-quality randomized controlled studies would be conducted in the future.

Funding sources: This work was supported by the National Natural Science Foundation of China (grant number 81873300); the Capital Health Research and Development of Special (grant number 2018-2-4173); the Fundamental Research Funds for the Central public welfare research institutes (grant number ZZ11-023).

Author Contributions: SJ Ma, MM Zhao, ZY Pan, J Fan participated in the concept and design of the judges. SJ Ma, MM Zhao, ZY Pan, J Fan used the search strategy. ZY Pan, J Fan used the selection criteria. SJ Ma, MM Zhao completed a bias risk assessment. SJ Ma, MM Zhao, ZY Pan, J Fan, XX Zhang analyzed and explained the data. This is a manuscript written by SJ Ma, MM Zhao. ZY Pan, J Fan and Y Zhang critically edited the manuscript. SJ Ma, MM Zhao, ZY Pan, J Fan, XX Zhang are in charge of the whole project.

Acknowledgments: Not applicable.

Conflicts of Interest: The authors declare no conflict of interest.

Ethical approval: This article does not contain any studies with human participants performed by any of the authors.

\section{References:}

1. Lankisch PG, Apte M, Banks PA. Acute pancreatitis. Lancet (London, England). 2015;386(9988):85-96.

2. van Dijk SM, Hallensleben NDL, van Santvoort HC, et al. Acute pancreatitis: recent advances through randomised trials. Gut.2017;66(11):2024-2032.

3. Roberts SE, Akbari A, Thorne K, Atkinson M, Evans PA. The incidence of acute pancreatitis: impact of social deprivation, alcohol consumption, seasonal and demographic factors. Alimentary pharmacology $\mathscr{E}$ 
therapeutics. 2013;38(5):539-548.

4. Banks PA, Bollen TL, Dervenis C, et al. Classification of acute pancreatitis-2012: revision of the Atlanta classification and definitions by international consensus. Gut. 2013;62(1):102-111.

5. Thoeni RF. Imaging of Acute Pancreatitis. Radiologic clinics of North America. 2015;53(6):1189-1208.

6. Moggia E, Koti R, Belgaumkar AP, et al. Pharmacological interventions for acute pancreatitis. The Cochrane database of systematic reviews. 2017;4(4):Cd011384.

7. IAP/APA evidence-based guidelines for the management of acute pancreatitis. Pancreatology : official journal of the International Association of Pancreatology (IAP) [et al]. 2013;13(4 Suppl 2):e1-15.

8. Dawra R, Sah RP, Dudeja V, et al. Intra-acinar trypsinogen activation mediates early stages of pancreatic injury but not inflammation in mice with acute pancreatitis. Gastroenterology.2011;141(6):2210-2217.e2212.

9. Hines OJ, Pandol SJ. Management of severe acute pancreatitis.BMJ (Clinical research ed). 2019;367:16227.

10. Leppäniemi A, Tolonen M, Tarasconi A, et al. 2019 WSES guidelines for the management of severe acute pancreatitis. World journal of emergency surgery : WJES. 2019;14:27.

11. Gao N, Yan C, Zhang G. Changes of Serum Procalcitonin (PCT), C-Reactive Protein (CRP), Interleukin17 (IL-17), Interleukin-6 (IL-6), High Mobility Group Protein-B1 (HMGB1) and D-Dimer in Patients with Severe Acute Pancreatitis Treated with Continuous Renal Replacement Therapy (CRRT) and Its Clinical Significance. Medical science monitor : international medical journal of experimental and clinical research. 2018;24:5881-5886.

12. Xu JCYTX, Correspondence A, J. Xu DDAYCHoW, Medical College QCEjc. Early Continuous VenoVenous Hemofiltration Is Effective in Decreasing Intra-Abdominal Pressure and Serum Interleukin-8 Level in Severe Acute Pancreatitis Patients with Abdominal Compartment Syndrome. Blood Purification. $2017 ; 44(4): 276-282$.

13. Chen XSMMXLXSW, Correspondence A, W. Sun DoICUADHo, Nantong University KWRDCE, fmtiy341@163.com. Effectiveness of continuous veno-venous hemofiltration in the treatment of severe acute pancreatitis. Experimental and Therapeutic Medicine. 2019;17(4):2720-2724.

14. Chen DJ,Gong MQ. Effect of continuous renal replacement therapy on biochemical and physiological parameters of severe acute pancreatitis.Int J Lab MED, 2018;5(39):555-558.doi: 10.3969/j.issn.16374130.2018.05.01

15. Chen FS. Clinical efficacy and value of continuous renal replacement therapy (CRRT) in patients with severe acute pancreatitis (AP).Chinese and Foreign women's Health study. 2020(12):47-8.

16. Cui WY, Xu HF, Li Y, et al. Evaluation of Early Continuous Renal Replacement Therapy in the Treatment of Severe Acute Pancreatitis:A Prospective Randomized Controlled Study. Lingnan Journal of Emergency Medicine. 2017;6(22):531-534.doi:10.3969/j.issn.1671-301X.2017.06.007.

17. Deng ZY, HeXD, Zhao XL,et al. Effect of continuous renal replacement therapy on cytokines in severe acute pancreatitis. People's Military Surgeon. 2014;10(57):1087-1089.

18. Hou CX, Qiao YJ. Clinical Observation of Routine Treatment Combined with Bedside Continuous Renal Replacement therapy in the Treatment of Severe Acute Pancreatitis Medical Information. 2018;13(31):107109. doi:10.3969/j.issn.1006-1959.2018.13.031

19. Hu W, Shu GS, Hu JX. Clinical efficacy of continuous renal replacement therapy for severe pancreatitis. Hunan Medical Journal. 2001(04):279-80.

20. Hui WJ, Bai W, Zhang HD. Efficacyevaluation ofearlyCRRT treatmentinpatientswith acute severe pancreatitis. Clinical medicine. 2017;3(2):44-45 
21. Ji HL, Tian R, Yan YJ, et al. Effects of continuous renal replacement therapy on C-reactive protein and adiponectin in patients with severe acute pancreatitis. Med J of Communications. 2011;25(04):378-9+81.

22. Li QB, Tong L, Cai SX. Study of continuous renal replacement therapy in patients with severe acute pancreatitis. Journal of Guangdong Medical College. 2009;27(05):501-3.

23. Li KY. Curative effect observation of early bedside hemofiltration in severe acute pancreatitis. Diet care. 2016;11(3):17-18.

24. Li LL. Effect of continuous renal replacement therapy in the treatment of severe acute pancreatitis. Practical Clinical Medicine. 2018;19(07):11-2+5.doi: 10.13764/j.cnki.lcsy.2018.07.004

25. Li Q. Clinical observation of continuous renal replacement therapy for severe acute pancreatitis. J Med Thero\&Prac. 2020;5(33):756-758.doi:10.19381/j.issn.10017585.2020.05.032

26. Li TT,Shi W. To Observe the Continuous Renal Replacement Therapy (CRRT) on Hyperlipidemia (HLSAP) in the Treatment of Severe Acute Panc. Diet care. 2018;3(5):1-2.

27. Li YP. Continuous renal replacement therapy for severe acute pancreatitis treatment effect research. Journal of Clinical and Experimental Medicine. 2014;13(17):1450-2.doi:10.3969/ j.issn.1671-4695.2014.17.023

28. Li YN, Xu F, Shu GS, et al. The protective effect of continuous renal replacement therapy on tissue and organ damage induced by severe pancreatitis. J clin Res.2002(04):126-7.

29. Liu JQ. Application and timing of continuous renal replacement therapy in patients with acute severe pancreatitis. Medical Equipment. 2019;32(10):106-7.

30. Liu MX,Liao L. Effects of continuous renal replacement therapy on severe acute pancreatitis with hyperlipidemia. Chongqing Med J. 2011;5(40):454-457.doi: 10. 3969/ j. issn. 1671-8348. 2011. 05. 016

31. Liu XS, Feng EZ. Application of CRRT in treatment of severe acute pancreatitis. Med J NDFNC. 2017;38(07):460-2.doi: 10.16021/j.cnki.1007-8622.2017.07.012

32. Ni ZH. Obseve of the effect of continuous renal replacement therapy to severe acute pancreatitis.[D].Jilin University,2013.

33. Peng B, Meng DZ, Huang XF. Effect of continuous renal replacement therapy on severe acute pancreatitis and its effect on inflammatory mediators and coagulation function. J Prev Med Chin PLA. 2019;37(05):51-2. doi:10.13704/j.cnki.jyyx.2019.05.025

34. Peng Y, Wen G, Peng XG, et al. Effects and Significance of Serum Amylase,TNF- $\alpha$, IL- $1 \beta$ and PCT in Patients with Severe Acute Pancreatitis After CRRT. Marker immunoassay and clinic. 2017;24(09):10114.doi: 10.11748/bjmy.issn.1006-1703.2017.09.014

35. Peng Y, Wu Q. Observation of effects on patients with severe acute pancreatitis by CVVH. China Medical Engineering. 2009;4(17):288-292.

36. Shen Q, Gan H, Li ZR, et al. Effect of continuous renal replacement therapy on intestinal mucosal barrier dysfunction induced by sever acute pancreatitis. Chongqing Med J. 2016;26(45):36403642.doi:10.3969/j.issn.1671-8348.2016.26.013

37. Sun JH, Xu DP. Effects of continuous renal replacement therapy on biochemical and physiological indexes of severe pancreatitis. Chinese and Foreign Medical Research. 2018;14(16):141-143.doi: 10.14033/j.cnki.cfmr.2018.14.060

38. Tang W, Xiao D, Liu Y, et al. Clinical Observation of Early Treatment of Severe Acute Pancreatitis with CRRT. Chinese and Foreign Medical Research. 2017;15(19):23-5.doi: 10.14033/j.cnki.cfmr.2017.19.011

39. Tian GX. Clinical evaluation of continuous renal replacement therapy in early stage of acute severe pancreatitis. Prac J MedPharm. 2016;7(33):612-613.doi:10.14172/j.issn1671-4008.2016.07.015 
40. Tian JX, Shen ZF, Hu D, et al. Clinical analysis of continuous renal replacement therapy for severe acute pancreatitis. Chinese and Foreign Medical Research. 2015;13(28):46-47.doi:10. 14033/ j.cnki .cfmr. 2015. 28. 022

41. Wan CS. The clinical effect and nursing experience of CRRT in treating severe acute pancreatitis. Electronic Journal of general clinical Surgery. 2017;5(04):78-81.

42. Wang LF. Clinical observation of CRRT in the treatment of severe acute pancreatitis. China Prac Med. 2020;15(26):63-5.doi: 10.14163/j.cnki.11-5547/r.2020.26.025

43. Wang LY. Clinical observation of conventional medical treatment combined with bedside continuous renal replacement therapy in the treatment of acute severe pancreatitis. Journal of Clinical Medical. 2017;4(60):11744-5.doi: 10.16281/j.cnki.jocml.2017.60.032

44. Wang XQ, Wang YY. The value of CRRT in treating severe acute pancreatitis with hyperlipidemia. China Prac Med. 2019;14(08):41-2.doi: 10.14163/j.cnki.11-5547/r.2019.08.021

45. Wang XM. Study on blood purification for severe acute pancreatitis. China Health Care\&Nutrition. 2016;4(26).doi:

46. Wang YF, Tao XG, Guo W, et al. Application of continuous veno venous hemodiafiltration(CVVHDF) in the treatment of hyperlipidemic severe pancreatitis. Journal of Hepatobiliary Surgery. 2017;25(05):342-4.

47. Wang Y, Miao SX, Chen ZS, et al. Effect of continuous renal replacement therapy on procalcitonin and prognosis in patients with severe acute pancreatitis. Zhejiang JITCWM. 2018;28(1):27-30

48. Wei R. Continuous veno-venous hemofiltration was performed in ICU patients with severe acute pancreatitis. Chinese and Foreign women's Health study. 2015;12:207.

49. Wu LM, Chen XX, Shen JM, et al. Clinical effectiveness of continuous renal replacement therpy for severe acute pancreatitis. Abdominal surgery. 2013;3(26):161-163.doi: 10.3969/j.issn.1003-55 91.2013.03.00

50. Wu SK, Kuang YQ, Luo WX, et al. Clinical observation of CRRT in elderly patients with severe acute pancreatitis. Guide of China Medicine. 2015;15:98-99.doi: 10.15912/j.cnki.gocm.2015.15.067

51. Xiao XP. Continuous renal replacement therapy for severe acute pancreatitis and nursing intervention. Contemporary Nurses (Academic edition). 2014;8:67-68.

52. Xu F, Geng H. Observation on the Therapeutic Effect of Early CRRT in ICU Patients With Severe Acute Pancreatitis. China Continuing Medical Education. 2019;20(11):114-116.doi: 10.3969/j.issn.16749308.2019.20.049

53. Xu Y, Zhu B, Liu n. Therapeutic outcomes of continuous renal replacement therapy(CRRT) for severe acute pancreatitis. Jiangsu Med J. 2009;10(35):1175-1176.doi: 10.19460/j.cnki.0253-3685. 2009.10.026

54. Xu GB, Zhang JB, Dong MP, et al. Analysis of efect of continuous renal replacement therapy in treatment of severe acute pancreatitis. Chin J Prim Med Pharm. 2013;20(17):2561-3.doi: 10.3760/cma.j.i ssn.1008 - 6706.2013.17.00 1

55. Xu JY. Clinical analysis of CRRT in treatment of severe acute pancreatitis with hyperlipidemia. Contemporary Nurse (Specialist edition). 2013;9:29-30

56. Yang H. A brief discussion on the treatment and clinical efficacy of acute pancreatitis. Seek Medical And Ask The Medicine(Second Half monthly). 2013;11(6):92-93.

57. Yu DZ, Huang MT, Tan JX, et al. Conventional medical treatment combined bedside continuous renal replacement therapy(CRRT) for severe acute pancreatitis(SAP). Journal of Youjiang Medical University for Nationalities. 2015;37(01):26-8. 
58. Zhang X, Lin M, Zhang LJ. Evaluation of therapeutic effect of CRRT on hyperlipidemia acute pancreatitis. Medical frontier. 2016;30(6):21-22.

59. Zhong X, Xiao XH. Protective Effect of CRRT on Hepatic and Renal Function of Patients with Severe Pancreatitis. Med Pharm J Chin PLA. 2017;29(04):99-102.doi:10.3969/j.issn.2095- 140X.2017.04.026

60. Zhou JY. Clinical effect of continuous renal replacement in patients with severe acute pancreatitis complicated by systemic inflammatory response syndrome. MedicalInformation. 2015;44:331.

61. Zhu CZ. ICU treatment and clinical significance of severe acute pancreatitis. The world Clinical Medicine. 2016;14(10):77-78.

62. Zhu JG, Yu HJ, Wang LE, et al. Clinical observation of continuous blood purification in the treatment of severe acute pancreatitis. Modern Practical Medicine. 2007;12(19):966-967.

63. Zou YD, Chen YS,Peng GS. Effect of early intervention for CRRT in acute severe pancreatitis. The word Clinical Medicine. 2019;4(13):82-83.

64. Zerem E. Treatment of severe acute pancreatitis and its complications. World journal of gastroenterology.2014;20(38):13879-13892.

65. Gunjaca I, Zunic J, Gunjaca M, Kovac Z. Circulating cytokine levels in acute pancreatitis-model of SIRS/CARS can help in the clinical assessment of disease severity. Inflammation. 2012;35(2):758-763.

66. Kaplan M, Ates I, Akpinar MY, et al. Predictive value of C-reactive protein/albumin ratio in acute pancreatitis. Hepatobiliary $\& 3$ pancreatic diseases international : HBPD INT. 2017;16(4):424-430.

67. Staubli SM, Oertli D, Nebiker CA. Laboratory markers predicting severity of acute pancreatitis. Critical reviews in clinical laboratory sciences. 2015;52(6):273-283.

68. Hong W, Lin S, Zippi M, et al. Serum Albumin Is Independently Associated with Persistent Organ Failure in Acute Pancreatitis. Canadian journal of gastroenterology $\& 3$ hepatology.2017;2017:5297143.

69. Karkar A, Ronco C. Prescription of CRRT: a pathway to optimize therapy. Annals of intensive care. 2020;10(1):32.

70. Takeda K, Takada T, Kawarada Y, et al. JPN Guidelines for the management of acute pancreatitis: medical management of acute pancreatitis. Journal of hepato-biliary-pancreatic surgery.2006;13(1):42-47.

71. Wang JW, Peng YM, Liu FY, Zhang H. [Effects of serum of patients with MODS on TF and PAI-1 secretion of human vascular endothelial cells during CRRT]. Xi bao yu fen zi mian yi xue za zhi $=$ Chinese journal of cellular and molecular immunology. 2009;25(6):534-536.

\section{Hosted file}

Table.pdf available at https://authorea.com/users/395157/articles/508467-the-clinicalefficacy-of-continuous-renal-replacement-in-the-treatment-of-acute-pancreatitis-a-metaanalysis-of-randomized-controlled-trials

\section{Hosted file}

Fig.pdf available at https://authorea.com/users/395157/articles/508467-the-clinicalefficacy-of-continuous-renal-replacement-in-the-treatment-of-acute-pancreatitis-a-metaanalysis-of-randomized-controlled-trials 